\title{
Towards sustainability: An assessment of an urbanisation bubble in China using a hierarchical - stochastic multicriteria acceptability analysis - Choquet integral method
}

\begin{abstract}
Urbanisation bubbles have become an increasingly serious problem. Attention has been paid to the speed of urbanisation; however, the issue of quality has been neglected, particularly in the case of China. Therefore, the aim of this research is to evaluate China's urbanisation bubbles by employing a hierarchical - stochastic multicriteria acceptability analysis (SMAA) - Choquet integral method. In order to highlight regional disparities, we measure the urbanisation bubbles at a provincial level. Our study aggregates the urbanisation bubble indices using the Choquet integral preference model, and considers the interactions between various indicators. Furthermore, robust ordinal regression and SMAA are applied to resolve the robustness issues associated with the entire set of weights assigned to the urbanisation bubble composite indicator. In addition, by employing a multiple criteria hierarchy process, the study aggregates urbanisation bubble indices not only at the comprehensive level, but also at the intermediate levels of the hierarchy. Our findings suggest that the ranking of urbanisation bubbles is positively related to the level of regional development. This study contributes to the evaluation of regional urbanisation and sustainable development.
\end{abstract}

\section{Keywords}

Urbanisation bubble; Sustainable urbanisation; Sustainable urban development; Sustainability; The hierarchical-SMAA-Choquet integral approach; China

\section{Highlights}

- This study contributes to the evaluation of regional urbanisation and sustainable development.

- A hierarchical - stochastic multicriteria acceptability analysis (SMAA) - Choquet integral method is employed.

- This study aggregates the urbanisation bubble indices and considers the interactions between various indicators.

- The research aggregates urbanisation bubble indices at both comprehensive and intermediate levels.

- The ranking of urbanisation bubbles is positively related to the level of regional development. 


\section{Introduction}

The $20^{\text {th }}$ and $21^{\text {st }}$ centuries have witnessed rapid urbanisation all over the world and urbanisation has been viewed as an important strategy for development (Shen and Zhou, 2014). In China, there has been a dramatic increase in urbanisation following reform and 'opening-up' in the late 1970s (Zhang and Li, 2012; Miao and Wu, 2016). China's urban population increased from 17.9\% of the total population in 1978 to over 57.31\% in 2016 (National Bureau of Statistics, 2017). With unprecedented speed, growing urbanisation has boosted China's economic prosperity (Friedmann, 2006; Dyson, 2011). However, rapid economic growth and urbanisation has been accompanied by a host of problems, such as environmental pollution (Fang, Wang and $\mathrm{Xu}, 2016$; Cao, Chen and Hickman, 2017; Wang et al., 2017), inefficient public services (Dyson, 2011), low living standards (Li et al., 2018), gentrification (Lees, Shin and Lopez-Morales, 2016; Zhang et al., 2019), and loss of arable land ( $\mathrm{Li}$ et al., 2014; $\mathrm{Li}, 2015$ ). These phenomena are a result of Chinese local government prioritising the speed of urbanisation over the quality (Zhou et al., 2015), and are collectively known as the urbanisation bubble (Wang, 2011; Xu, 2004). This kind of urbanisation is contrary to the principles of regional sustainable development which is a significant component of development processes in human society and the foundation of global or national sustainable development ( $\mathrm{Lu}$ and Liu, 1998). Within the complex natural socio-economic ecosystem, the aim of regional sustainable development is to contribute to the harmonious development of regional economic, societal and natural components (Dong et al., 2015). Thus, urbanisation bubbles result in a mismatch between expansion of the urban population and urban infrastructure development, and between urbanisation and industrialisation, and may also lead to conflict between urban and rural residents (Fu, Liu and Zhao, 2012). Moreover, the urbanisation bubble causes a discrepancy between economic growth and land use (Zhou, Zhang and Shen, 2015). For instance, although the average annual growth rate of urban construction land in China was 15\% between 1981 and 2011, the annual economic growth rate was far below $15 \%{ }^{1}$. In addition, the urbanisation bubble is responsible for a number of other serious problems, such as resource depletion, population growth, and environmental pollution. The aforementioned issues relating to unsustainability have a significant negative effect on social advancement and economic growth within a region (Qi, Cheng and Shen, 2000). Therefore, in order to integrate the development of the economy, society and nature into regional sustainable development (Zhao et al., 1999), there is an urgent need to evaluate the urbanisation bubble.

In order to address the issues identified above, a sustainable approach to urbanisation is required, which will contribute to healthy urban development (Zhao, 2010). A series of studies have tried to seek effective tools with which to assess sustainable urbanisation, such as a hybrid heterogeneous DEA method (Ji et al., 2018), and a hybrid Entropy-McKinsey matrix method (Shen et al., 2016). For example, based on the Case-Based Reasoning (CBR) method, Wang et al. (2019) constructed a Lessons Mining System (LMS) designed to help mine lessons learned from previous practice, and suggested that LMS can be of use in understanding the potential problems associated with urbanisation by referring to the lessons that have been previously experienced in similar circumstances. From the perspective of sustainable development and new urbanisation theory and practice, Liu et al. (2019) developed an evaluation model of comprehensive system dynamics-data

1 The results are calculated based on the data derived from the China Statistical Yearbook 2012. 
envelopment analysis (SD-DEA), which can be used to create a green town development model using the system dynamics method. Similarly, Tan et al. (2018) employed a system dynamics model, consisting of four sub-systems of economic, social, environment and resource sectors to simulate urban sustainability performance, and show how the systemic interactions can be modelled by taking Beijing as a case study. However, these existing studies have several shortcomings: (1) although some studies have examined the interactions between different systems, they cannot capture the interactions between various indicators; (2) because these studies typically involve some degree of imprecision, they may lead to the elicitation of the parameters of composite indices. Moreover, because most existing studies overlook critical points, there will inevitably be a degree of approximation in the process of indices computation; (3) although some studies have attempted to evaluate sustainable urbanisation, few studies have assessed the urbanisation bubble from the reverse perspective. For instance, Wang (2011) explored the urbanisation bubble for 35 Chinese cities during the period from 1999 to 2008, and concluded that although the bubble phenomenon is not a prominent feature of their living environments, Chinese cities generally show a bubble tendency. However, the study does not include a specific and reliable method for measuring the urbanisation bubble and therefore cannot help us to understand the process underlying the phenomenon (Zhou, Zhang and Shen, 2015). In order to address this point, Zhou, Zhang and Shen (2015) employed the four quadrants measurement model to quantitatively evaluate China's urbanisation bubble. Nonetheless, although this study is useful, it does not distinguish between China's heterogeneous regions.

Therefore, this study aims to quantitatively evaluate China's urbanisation bubble by employing a hierarchical - Stochastic Multicriteria Acceptability Analysis (SMAA) - Choquet integral method. More specifically, it addresses the following two research questions: 1) how to design an indicator system with which to measure an urbanisation bubble; and 2) how can a hierarchical-SMAAChoquet integral method be applied to evaluate urbanisation bubbles' rankings? Our study contributes to the existing literature in the following ways. First, we explore the previously underresearched field of the urban bubble, rather than directly assessing sustainability; additionally, in order to highlight regional disparities, our urbanisation bubble measure is applied at the provincial level. Moreover, this study develops a complete indicator system and indicator hierarchy. Specifically, we focus on the urbanisation bubble composite indices not only at a comprehensive level, but also at a sub-indicator level, in terms of the environment, economy and society. Furthermore, in terms of methodology, we employ a new composite index approach - the hierarchical-SMAA-Choquet integral method - which can compute the interaction effects between indicators; the proposed method is able to avoid the elicitation of the parameters of composite indices, and take critical points into consideration. The Choquet integral is an aggregation process and is more complex than the sum of common weights (Grabisch, 1996). Although indicators can reflect the significance of the urbanisation bubble, a standard weighted sum is incapable of capturing redundancy and synergy between these indicators (Silvia et al., 2018). However, the Choquet integral method allows indicators to interact in the form of redundancy or synergy. This interaction between indicators enables the poor assessment of some indices to be compensated with the more accurate assessment of other indices (Marichal, 2004) which can make a significant difference in terms of obtaining composite indices when evaluating sustainability (Munda, 2005). The index weights of the Choquet integral is calculated from the participation of stakeholders and third parties. 
Changing the weight plurality will lead to a change in the ranking variability of the composite index. It involves Robust Ordinal Regression (ROR) and SMAA, which can be included in the Choquet integral (Angilella et al., 2010, 2012). In terms of robustness, ROR helps to obtain the necessary preference relation and the possible preference relation (Giarlotta and Watson, 2013). In addition, SMAA provides a probabilistic ranking by employing Rank Acceptability Indices (RAIs), which gives the probability of picking one set of compatible weights, and Pairwise Winning Indices (PWIs), which gives the probability of one unit obtaining a better value than another (Silvia et al., 2018). Index hierarchy is an inevitable issue in the fields of sustainable development, environmental governance and performance evaluation. Existing studies have extensively discussed the application of MCDA (Corrente, Greco and Słowiński, 2013, 2016) and, as a result, they proposed a new method known as the Multiple Criteria Hierarchy Process (MCHP). Thus, combining the MCHP with the Choquet integral linked to SMAA and ROR, results in the hierarchical-SMAA-Choquet integral method (Angilella et al., 2016).

This study is organised as follows. Section 2 presents a literature review on sustainable urbanisation and the urbanisation bubble. Section 3 introduces our methodology, including indicators and their measurement, as well as explaining, and expanding upon, the method used. The results and findings are provided in Section 4, while Section 5 offers conclusions.

\section{Literature review}

\subsection{Sustainable urbanisation}

The rapid increase in the level of urbanisation has resulted in serious concerns about urban sustainability (Isendahl and Smith, 2013; Cohen, 2017), because sustainable urbanisation is compatible with the principle of sustainable development (Roy, 2009; Ochoa et al., 2018). Urban sustainability is a measure that can be used to assess the sustainability of a city (Huang, Wu and Yan, 2015) and, consequently, sustainable urbanisation has emerged as a dynamic procedure that takes various environmental, social, economic and governance factors into consideration (Mori and Yamashita, 2015). After the economic reforms and 'opening-up' policy were implemented in 1978, China has experienced a period of dramatic growth in urbanisation (Li et al., 2018). The level of urbanisation has increased from less than $20 \%$ in 1978 to a predicted $60 \%$ in 2020 (Liu, Su and Jiang, 2016). Due to this rapid urbanisation, China has made great progress in terms of infrastructure improvements, the upgrading of social services and economic growth. However, a number of developmental problems have emerged (Zhai et al., 2019), including an unbalanced economic structure (Chen, 2007), regional imbalances (Wei, 2013), and environmental damage (Tan, Xu and Zhang, 2016). In addition, China also faces many serious challenges in respect of improving people's quality of life, and addressing ecological degradation and economic development (Zhai et al., 2019). Therefore, although sustainable development poses a huge challenge, pursuing it has become an urgent priority and a key component of national strategy in China (Zhang, Yuan and Tian, 2019).

Given the concerns about achieving sustainable urbanisation, it is vital to be able to evaluate it effectively. We first review several types of indices that have been used to measure sustainable 
urbanisation in existing studies. Because there are various perspectives on sustainable urbanisation - primarily social, economic and environmental - multiple methods can be used to assess sustainability, according to the respective research aims (Zhou et al., 2015; Ng, Cook and Chui, 2001). A number of researchers have conducted a comprehensive literature review and developed a series of frameworks with which to assess urban sustainability. Tan, Xu and Zhang (2016) put forward six perspectives with which to assess sustainable urbanisation in China: ecoenvironmental protection; land development; energy utilisation; population growth and migration; housing; and policy. These six perspectives can be regarded as a new and comprehensive method for evaluating urban sustainability in China. Similarly, Cohen (2017) conducted a systematic review, focusing on urban sustainability and produced a chart showing current studies on the assessment of urban sustainability. According to Cohen's (2017) results, the majority of relevant research still tends to use the three pillars (i.e. economic, social and environmental sustainability) model to analyse urban sustainability. Although there are flaws in the framework, the three pillars model has been widely used. In addition, some studies have linked sustainable urbanisation to smart cities, because it plays a vital role in urban planning and smart city development (Ibrahim, El-Zaart and Adams, 2018). A smart city needs a highquality infrastructure designed to tackle sustainability challenges and improve the quality of life (Caragliu, Del Bo and Nijkamp, 2011). Moreover, urban sustainability and smart cities share very similar goals: the smart city aims to achieve sustainability and a high quality of life for individuals (Tampouridou and Pozoukidou, 2018). It is evident that smart cities have a strong impact on the objectives of urban sustainability.

Regarding the assessment tools, fuzzy set theory can also be used to assess sustainable development. Although sustainable development is an objective concept, fuzzy set theory can link human expectations of development, contributing to empirical support for decision making within the context of sustainable development (Cornelissen, Berg, Koops, Grossman and Udo, 2001). In addition to fuzzy set theory, a hybrid Entropy-McKinsey Matrix method can also be applied to assessing sustainable urbanisation (Shen, Zhou, Skitmore and Xia, 2016), because it is helpful in terms of locating the urbanisation state point. Overall, these study tools can capture progress over time, because they have moved on from a static population analysis to taking advantage of operations research, quantitative methods and systems science (Zhang et al., 2020). For example, using an earth observation based multi-scale assessment, and collecting cultural, geographic, and economic data, some studies have explored regional and international patterns, situations, and development trends relating to urbanisation (Chen, 2015). Apart from the aforementioned assessment tools, there are also a number of indicator systems that can be used to measure sustainable urbanisation (Tan, Xu and Zhang, 2016). Among the various indicators, income level has close associations with development problems within the context of rapid urbanisation. In fast-growing cities, people on low and middle incomes seem to encounter more serious problems as a result of rapid urbanisation (Roy, 2009). Education is another important indicator. Education enables people to gain knowledge and abilities and then obtain a job and become urban citizens (Schwartz, 1973; Newbold, 1998). Individual age also plays a significant role in migration mobility and a city's development. A large number of talented young people tend to move to China's first-tier cities such as Beijing, Shanghai and Guangzhou, but older adults prefer to stay in the places where they grew up (Zhang, 2010). Young adults usually 
pursue their career development in cities and thus they are the main subjects in urban sustainability studies, though they face air pollution and traffic problems in cities (Zhang, 2010). Additionally, there is emerging research investigating urban sustainability at an individual level. For example, a sustainable city usually pays attention to eco-environmental protection, the appropriate use of resources, citizens' welfare and achieving satisfactory standards of living (Shen, Ochoa, Shah and Zhang, 2011).

Most existing sustainable urbanisation studies that use composite indicators and tools have focused on the inter-relationships between politics, economy and society. These studies have raised some important concerns. The first is the construct complexity of sustainable urbanisation. The characteristics of multi-levels, cause effect relationships and interaction effects have been discussed (McLellan, Chapman and Aoki, 2016; Sun, Liu and Zhao, 2019). However, these studies do not allow the full complexity of composite indicators to be constructed, resulting in a significant degree of vagueness. This fuzziness seriously undermines the quality and usefulness of the indicators obtained, because almost none of the indicators are clearer than the concept they aim to quantify (Silvia et al., 2018). Moreover, these existing studies do not distinguish between inputs, outcomes, and tools (Croes, 2011). The second concern is that the methodological building procedure of sustainable urbanisation may be inappropriate or unclear. For example, few studies have employed weighting procedures and interactions between indicators at different levels in evaluating sustainable urbanisation, which means that the model and results are unlikely to be very robust. In addition, the elicitation of the parameters of composite indices constitutes a problem due to the methods and composite indicators lacking explanatory and predictive capacity (Mazanec and Ring, 2011).

\subsection{Urbanisation bubble}

The term 'bubble' was first put forward in the field of economics (Hommes, Sonnemans, Tuinstra, and van de Velden, 2008; Nneji, Brooks and Ward, 2013), and Palgrave (1987) explained that an economic bubble refers to the process whereby a rapid rise in asset prices suddenly collapses. This definition has been supported by many studies, such as those by Smith, King, Williams and Boening (1993), Nneji, Brooks and Ward (2013), and Painter and Yu (2013). According to their arguments, China's economic bubble is a serious issue. Although China's economy has witnessed rapid growth, this growth cannot lead to a corresponding improvement in people's living standards and income levels (Ling, 1998; Lu, 1998). Regarding the phenomenon of urbanisation bubbles, existing studies have mainly focused on the following fields: housing, population, land, industrialisation and the social welfare bubble.

A housing bubble exists in representative Chinese cities, providing evidence of the unsustainability of the urbanisation process (Zhi et al., 2019). Teng, Chang and Chen (2017) examined both fundamental and bubble housing prices. They concluded that the housing bubble forced rising house prices to spread and that there is a greater probability of a crisis caused by the bubble bursting in the suburbs where bubble spread can occur. From a demographic perspective, Zhao (2005) examined the urbanisation bubble in terms of the growing percentage of the urban population as a proportion of the total population during a given time interval. However, the process of urban 
population growth cannot improve the quality of life for urban migrants, and hence results in an urbanisation bubble (Zhou, Zhang and Shen, 2015). Based on urban population growth, a land bubble is defined as occurring when the speed of urban land expansion exceeds the rate of population expansion in the process of urbanisation (Ren and Li, 2006). Furthermore, a land bubble can have a detrimental effect on social welfare and lead to inefficient overinvestment (Miao, Wang and Zhou, 2015). Because the speed of urbanisation speed exceeds that of industrialisation, there is a discrepancy between economic industrialisation and urbanisation development, which is known as an industrialisation bubble (Zhou, Zhang and Shen, 2015). It is closely related to environmental sustainability and human civilisation (Palit, 2014). In addition, some studies have discussed the phenomenon of urbanisation bubbles from a social welfare perspective. For example, Shome (2013) indicated that urban infrastructure plays an important role in the success of a city. Similarly, Ejaro and Abubakar (2013) argued that a social welfare bubble entails a city not being able to provide suitable public services to urban migrants in the process of urbanisation.

However, the existing studies do not use systematic or intelligent tools to assess urbanisation bubbles. The foregoing discussion about urbanisation bubbles indicates that urbanisation development should focus on sustainability and achieving a balance between the economy, society and the environment. In other words, we need to avoid urbanisation bubbles in order to improve sustainable urbanisation. The lack of evaluation of urbanisation bubbles has not only resulted in a disequilibrium in the relationships between population increase, land use, public services and infrastructure and industrial development, but also makes it much more difficult for urban planners and managers to choose the most appropriate urbanisation strategy. Thus, our study offers a suitable approach with which to address this issue and evaluate the urbanisation bubble phenomenon more comprehensively.

\section{Methodology}

In this study, we examine cases at the provincial level, namely 22 provinces, 5 autonomous regions and 4 municipalities. Generally, this kind of analysis is effective on a regional scale. We chose Chinese provinces as cases based on the following considerations. Evaluation at the provincial level can enable the results from the decision model to be directly understood in the process of interpreting the territory (Silvia, Pierluigi and Salvatore et al., 2018). Moreover, it is reasonable to make the change from regional to provincial level in our study, because the complexity of China's provinces is the same as its regions with respect to their social relationships, quality and variety of resources. Previous studies have indicated a privileged observation for the evaluation of China's urbanisation bubble because of obviously differing socio-economic situations at the provincial level, such as the actual benefits of people's living standards, industrial structure, and income (Ling, 1998; Lu, 1998; Xiong, 1998; Silvia, Pierluigi and Salvatore et al., 2018). In addition, China is facing issues of unsustainability and imbalance associated with the process of urban development (Xu, 2004; Zhang, 2006). For example, provinces in Western China are characterised by significant backwardness, more specifically economic underdevelopment and poor eco-environmental conditions, as well as a low anthropic dimension (Ke, Chen and Robson et al., 2015; Ahmad et al., 2018). Based on the above analysis of the highly contrasting and variegated features of China's provinces, there is no methodological defect associated with undertaking the study at the provincial 
level.

The aim of our study is to evaluate the urbanisation bubble for 22 provinces, 5 autonomous regions, and 4 municipalities in China by employing the hierarchical-SMAA-Choquet integral method. All cases are listed in Table 1.

Table 1 Code and province listing

\begin{tabular}{|l|l|l|l|l|l|}
\hline Code & Province & Code & Province & Code & Province \\
\hline $\mathrm{a}_{1}$ & Anhui & $\mathrm{a}_{12}$ & Henan & $\mathrm{a}_{23}$ & Shanghai \\
\hline $\mathrm{a}_{2}$ & Beijing & $\mathrm{a}_{13}$ & Hubei & $\mathrm{a}_{24}$ & Shaanxi \\
\hline $\mathrm{a}_{3}$ & Chongqing & $\mathrm{a}_{14}$ & Hunan & $\mathrm{a}_{25}$ & Shanxi \\
\hline $\mathrm{a}_{4}$ & Fujian & $\mathrm{a}_{15}$ & $\begin{array}{l}\text { Inner } \\
\text { Autonomous Region }\end{array}$ & $\mathrm{a}_{26}$ & Sichuan \\
\hline $\mathrm{a}_{5}$ & Gansu & $\mathrm{a}_{16}$ & Jiangsu & $\mathrm{a}_{27}$ & Tianjin \\
\hline a6 & Guangdong & $\mathrm{a}_{17}$ & Jiangxi & $\mathrm{a}_{28}$ & Tibet Autonomous Region \\
\hline a7 & Guangxi Zhuang Autonomous & $\mathrm{a}_{18}$ & Jilin & $\mathrm{a}_{29}$ & Uygur \\
\hline a8 & Gegion & Autonomous \\
\hline a9 & Hainan & $\mathrm{a}_{19}$ & Liaoning & $\mathrm{a}_{30}$ & Yunnan \\
\hline a10 & Hebei & $\mathrm{a}_{20}$ & Ningxia Hui Autonomous & a 31 & Zhejiang \\
\hline a11 & Heilongjiang & $\mathrm{a}_{21}$ & Qinghai & & \\
\hline
\end{tabular}

\subsection{Indicator system for urbanisation bubble}

Based on the studies by Zhou, Zhang and Shen (2015), the study selects indicators from the perspectives of the economy (ED), the environment (EL) and society (SD) to describe the urbanisation bubble in detail. We employ the ratio of urban dwellers to the total number of dwellers at the provincial level to measure the urbanization rate (UR), and a change in UR can reflect residents' dynamic migration from a rural area to an urban area (Zhou et al., 2005). The change in urbanization rate during the period between time $t_{1}$ and $t_{2}$ can be obtained by the following equation:

$$
C_{U R}=\frac{T_{U R_{t_{2}}}^{\prime}-T^{\prime}{ }_{U R_{t_{1}}}}{t_{2}-t_{1}}=\frac{\Delta T^{\prime}{ }_{U R}}{\Delta t}
$$

Where $C_{U R}$ is the value of urbanisation velocity; $T^{\prime}{ }_{U R_{t_{2}}}$ and $T^{\prime}{ }_{U R_{t_{1}}}$ represent the normalisation values of UR at time $\mathrm{t}_{1}$ and $\mathrm{t}_{2}$ respectively; $\Delta T_{U R}^{\prime}$ means the urbanization rate change during a time interval; $\Delta t$ is the time interval increment.

Zhou, Zhang and Shen (2015) suggested that the urbanisation bubble means a transformation where there is a systematic deviation in the urbanisation rate in terms of measurement indicators. We use $\mathrm{C}_{\mathrm{ED}}, \mathrm{C}_{\mathrm{EL}}$ and $\mathrm{C}_{\mathrm{SD}}$ to describe this deviation. Therefore, the urbanisation bubble can be identified using the following formulae: 


$$
\text { Bubble }_{E D}=\frac{C_{U R}}{C_{E D}} \quad \text { Bubble }_{E L}=\frac{C_{U R}}{C_{E L}} \quad \text { Bubble }_{S D}=\frac{C_{U R}}{C_{S D}}
$$

\subsubsection{Economic development (ED)}

Population (PB). This refers to the inflow of population from rural areas to urban areas. Due to China's household registration system, migrant workers are not recognised as urban residents, and they cannot obtain the same social welfare benefits as urban residents, which may lead to a population bubble. Thus, in order to avoid a population bubble, the increase in urban population should be synchronised with the process of urbanisation (Zhou, Zhang and Shen, 2015). This indicator is measured by the percentage of registered urban residents as a proportion of the overall urban population. According to Zhou, Zhang and Shen (2015), the PB varies during the process of urbanization. Thus, $\mathrm{C}_{\mathrm{PB}}$ is employed to test the significance of the percentage change over a period of time from $t_{1}$ to $t_{2}$ :

$$
C_{P B}=\frac{T_{P B t_{2}}^{\prime}-T^{\prime}{ }_{P B_{t_{1}}}}{t_{2}-t_{1}}=\frac{\Delta T_{P B}^{\prime}}{\Delta t}
$$

Where $\mathrm{C}_{\mathrm{PB}}$ refers to the percentage velocity of the registered urban population. $T_{P B_{t_{2}}}^{\prime}$ and $T_{P B_{t_{1}}}^{\prime}$ are the normalization values at time $t_{1}$ and $t_{2}$, respectively. $\Delta T_{P B}^{\prime}$ is the ratio difference at the specified time interval $(\Delta t)$ of the registered urban population.

Construction land (CI). Zhou, Zhang and Shen (2015) showed that urban construction land is expanding faster than the population, indicating that a disequilibrium exists between urban population and land expansion, and thus, a land use bubble appears. The value of $\mathrm{CI}$ varies during the process of urban expansion, and thus there are different values of CI at different stages of urbanization. We selected the velocity $\left(\mathrm{C}_{\mathrm{CI}}\right)$ of construction land area to measure the urban land use bubble.

$$
C_{C I}=\frac{T^{\prime}{ }_{C I_{t_{2}}}-T^{\prime}{ }_{C I_{t_{1}}}}{t_{2}-t_{1}}=\frac{\Delta T_{C I}^{\prime}}{\Delta t}
$$

Industrialisation level (II). When the pace of urbanisation is inconsistent with the speed of industrial development, industrial bubbles will emerge (Zhou, Zhang and Shen, 2015). The existing studies usually use the percentage of industrial production in GDP to measure the industrialisation level (Yang et al., 2005; Wang and Wu, 2006). In the process of urbanisation development, II refers to a specific value of industrialisation level at a given time. $\mathrm{C}_{\mathrm{II}}$ is employed to test whether there is a significant change in the industrialisation development level from $t_{1}$ to $t_{2}$. 


$$
C_{I I}=\frac{T^{\prime}{ }_{I t_{2}}-T^{\prime}{ }_{I I} t_{1}}{t_{2}-t_{1}}=\frac{\Delta T_{I I}^{\prime}}{\Delta t}
$$

Where, $T^{\prime}{ }_{I t_{2}}$ and $T^{\prime}{ }_{I I_{t_{1}}}$ denote the normalisation values of the industrialisation level (II) at $\mathrm{t}_{1}$ to $\mathrm{t}_{2}$ respectively, and $\Delta T^{\prime}{ }_{I I}$ is the change in industrial development during a specific time interval.

Agricultural modernisation (AM). Similarly to an industrialisation bubble, an agricultural modernisation bubble means that the balance between the speed of urbanisation development and agricultural modernisation is disturbed (Zhou et al., 2015). Following the existing studies (Guo and Li, 2003; Ma and Gong, 2010; Xin and Jing, 2010), we use agricultural land productivity to measure agricultural modernisation $\left(\mathrm{C}_{\mathrm{AM}}\right)$. Thus, the velocity of agricultural modernisation can be measured as follows:

$$
C_{A M}=\frac{T^{\prime}{ }_{A M_{t_{2}}}-T^{\prime}{ }_{A M_{t_{1}}}}{t_{2}-t_{1}}=\frac{\Delta T^{\prime}{ }_{A M}}{\Delta t}
$$

Where, $T_{A M_{t_{2}}}^{\prime}$ and $T_{A M_{t_{1}}}^{\prime}$ are the normalisation values of agricultural modernisation (AM) at $\mathrm{t}_{1}$ to $\mathrm{t}_{2}$, respectively, and $\Delta T^{\prime}{ }_{A M}$ is the change in agricultural modernization during a specific time interval.

\subsubsection{Environment level (EL)}

An environment bubble in the process of urbanisation means that environmental pollution caused by urbanisation has already jeopardized the health of residents. In other words, if the level of environmental governance cannot keep up with the rate of urbanisation, an environment bubble would be inevitable. A set of indicators was chosen to measure the environment level (EL) within the process of urbanization as follows: green area per capita (GA); number of days with good or above good air quality (AQ); and environmental pollution control investment (EP) (Zhou, Zhang and Shen, 2015; Gao et al., 2018). The various environmental indicators will have specific values at given time points within the process of urbanization. The change in the environment level can be calculated by the following equation

$$
C_{E L}=\frac{T_{E L_{2}}^{\prime}-T_{E L_{t_{1}}}^{\prime}}{t_{2}-t_{1}}=\frac{\Delta T_{E L}^{\prime}}{\Delta t}
$$

Where $T_{E L_{t_{2}}}^{\prime}$ and $T_{E L_{t_{1}}}^{\prime}$ are the EL values after normalisation at time $\mathrm{t}_{1}$ and $\mathrm{t}_{2}$, respectively; $\Delta T_{E L}^{\prime}$ is the variation in the environment level over a specified time interval. 


\subsubsection{Social development (SD)}

A social development bubble indicates that the level of social development cannot meet the demands of the speed of urbanisation growth and urban expansion. Based on the existing studies (Li and Xia, 2006; Pan and Ma, 2007), we chose the following indicators to measure the level of social development (SD) within the process of urbanization: density of drainage pipeline (DP); urban road space per capital (RS); and internet users per 100 of the population (IU). These indicators focus on the urban infrastructure and facilities which are closely related to the social welfare of urban residents (Zhou, Zhang and Shen, 2015). The various indicators each have a specific value at a given time point in the process of urbanisation. Thus, the velocity of social development from $t_{1}$ to $t_{2}$ can be measured by the following equation:

$$
C_{S D}=\frac{T^{\prime} S D_{t_{2}}-T^{\prime} S D_{t_{1}}}{t_{2}-t_{1}}=\frac{\Delta T^{\prime} S D}{\Delta t}
$$

Where $C_{S D}$ refers to the velocity of the social development level within the process of urbanization; $T_{S D_{t_{2}}}^{\prime}$ and $T_{S D_{t_{1}}}^{\prime}$ are the normalisation values of $\mathrm{SD}$ at time $\mathrm{t}_{1}$ and $\mathrm{t}_{2}$, respectively; $\Delta T_{S D}^{\prime}$ denotes the change in the level of social development during a specified time interval.

The data used in this study were derived from the official Statistical Yearbooks of every province in China from 2000 to 2017.

\subsection{Hierarchical-SMAA-Choquet integral}

Some studies have examined urban sustainability from the perspectives of data, indices and information (Mayer, 2008; Dahl, 2012; Singh et al., 2012). Silvia et al. (2018) suggested that the "dashboard approach" employed by the aforementioned studies, meaning that they control for the collection of diversified indicators, is inadequate. The composite indices combined on the indicators dashboard to produce a meaningful aggregation are necessary to measure progress towards goals. Composite indices have been used in a number of research areas, such as economic evaluation (Bandura, 2008), sustainable development (Silvia et al., 2018), tourism construction (Mendola and Volo, 2017), and innovation development (Grupp and Mogee, 2004). Our assessment of the urbanisation bubble comes within the field of sustainable development, and composite indices are a key feature of the modelling process (Böhringer and Jochem, 2007; Singh and Murty, 2012). When using composite indices, some critical questions should generally be considered, in particular: index weight, index aggregation, the robustness of the model and results, different index levels, and participation of stakeholders (Nardo et al., 2005; Greco et al., 2017). Multiple Criteria Decision Analysis (MCDA) focuses on the points discussed above and has been applied in sustainable development (Rowley et al., 2012; Cinelli et al., 2014; Gao et al., 2018). Based on MCDA, Silvia et al. (2018) put forward an advanced methodology for calculating composite indices, known as the hierarchical-SMAA-Choquet integral, which is able to deal with the aforementioned critical questions by adhering to the semantics of the problem at hand. We therefore chose the hierarchicalSMAA-Choquet integral to evaluate China's urbanisation bubble in our study. 
Figure 1 depicts the process involved in the hierarchical-SMAA-Choquet integral, which is employed to evaluate issues associated with the urbanisation bubble in China. In this study, we first introduce the Choquet integral preference model, and then the Non-additive robust ordinal regression (NAROR). SMAA is then explained. Based on SMAA, we explore the interaction between the MCHP and the Choquet integral preference model. Lastly, we obtain the hierarchicalSMAA-Choquet integral by applying NAROR and SMAA to the hierarchical Choquet integral preference model. Silvia et al. (2018) and Salvatore Corrente et al. (2016) provided a detailed discussion on how this method developed.

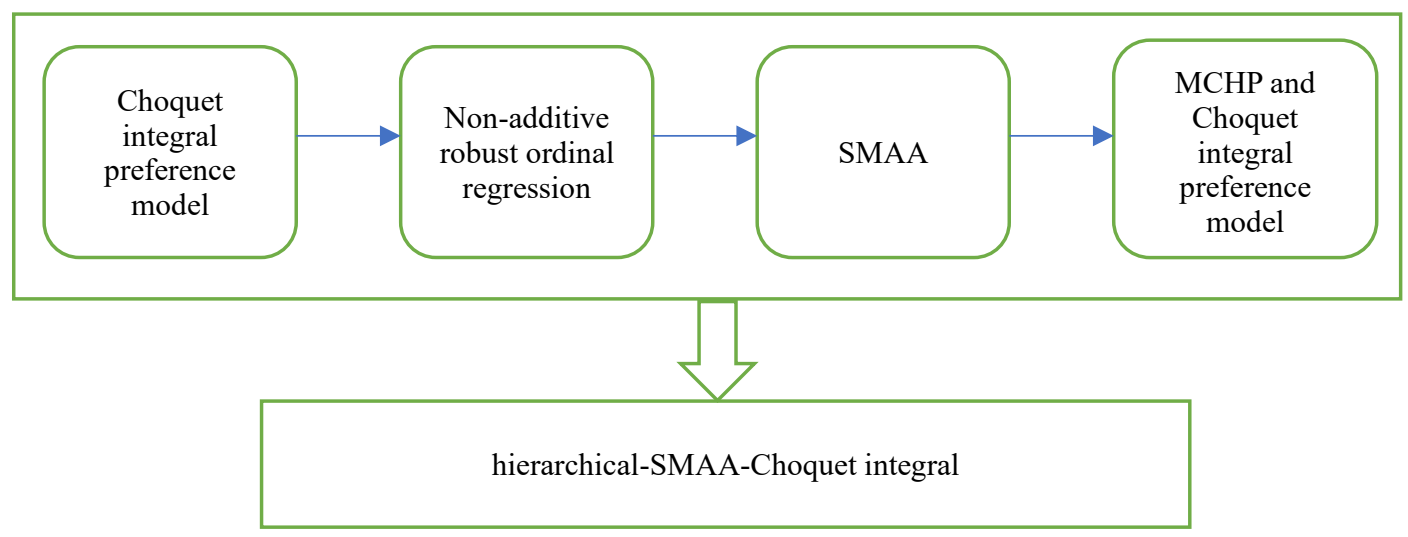

Figure 1 Development process of the hierarchical-SMAA-Choquet integral method

$\mathrm{G}$ is a family of assessments indicators and $G=\left\{g_{1}, \ldots, g_{n}\right\}$. The Choquet integral is defined as follows:

$$
C_{\mu}(a)=\sum_{i=1}^{n}\left[\left(g_{(i)}(a)-g_{(i-1)}(a)\right) \mu(\{(i), \ldots,(n)\})\right]
$$

Where subscripts (.) reorders the criteria in such a way that $g_{(1)}(a) \leq \cdots \leq g_{(n)}(a)$ and $g_{(0)}(a)=0 ; I=\{1, \ldots, n\}$, and $i \in I$. Considering the Möbius representation of a capacity $\mu$ is useful, and the function is $m: 2^{G}=\left[R\right.$ such that, for all $\left.S \subseteq 2^{G}\right]$,

$$
\mu(S)=\sum_{R \subseteq S} m(R)
$$

Equality has the following constraints:

$$
m(\varnothing)=0 ; \sum_{T \subseteq G} m(T)=1 ; \sum_{T \subseteq S} m\left(T \cup\left\{g_{i}\right\}\right) \geq 0 \text { for all } g_{i} \in G \text { and } S \subseteq G \backslash\left\{g_{i}\right\}
$$


According to the Möbius representation of $\mu$, the Choquet integral can also be expressed as follows (Gilboa and Schmeidler, 1994):

$$
C_{\mu}(a)=\sum_{T \subseteq G} m(T) \operatorname{ming}_{i}(a)
$$

Due to the interaction between indicators, the importance of an indicator is not only linked to its own relevance, but also to its significance to all the indicators' coalitions (Silvia et al., 2018). According to the Shapley value (Shapley, 1953), these features of an indicator can be represented as follows:

$$
\varphi\left(\left\{g_{i}\right\}\right)=\sum_{T \subseteq G \backslash\left\{g_{i}\right\}} \frac{(|G-T|-1) !|T| !}{|G| !}\left(\mu\left(T \bigcup\left\{g_{i}\right\}\right)-\mu(T)\right)
$$

The relationship between two distinct indicators $\left(g_{i}\right.$, and $\left.g_{j}\right)$ can also be assessed by calculating their interaction indicator (Murofushi and Soneda, 1993):

$\varphi\left(\left\{g_{i}, g_{j}\right\}\right)=\sum_{T \subseteq G \backslash\left\{g_{i}, g_{j}\right\}} \frac{(|G-T|-2) !|T| !}{|G| !}\left(\mu\left(T \cup\left\{g_{i}, g_{j}\right\}\right)-\mu\left(T \cup\left\{g_{i}\right\}\right)-\mu\left(T \cup\left\{g_{j}\right\}\right)+\mu(T)\right)$

Möbius representations allow the two equations above to be simplified (Grabisch, Marichal and Roubens, 2000):

$$
\begin{gathered}
\varphi\left(\left\{g_{i}\right\}\right)=\sum_{g_{i} \in A \subseteq G} \frac{m(A)}{|A|} \\
\varphi\left(\left\{g_{i}, g_{j}\right\}\right)=\sum\left\{g_{i}, g_{j}\right\} \subseteq A \subseteq G \frac{m(A)}{|A|-1}
\end{gathered}
$$

If the Choquet integral preference model is applied directly, it must meet the elicitation of $2^{|G|}-2$ parameters. However, it is unfeasible to undertake a large number of parameter calculations. In order to overcome this problem, q-additive capacity is introduced to make the application of the model realistic (Grabisch, 1997). Silvia et al. (2018) argued that the condition of $q=2$ seems to be unrestrictive in the majority of real applications, and there is an obvious advantage in that 2-additive capacity only requires a limited number of parameters. There are three constraints when we employ 2 -additive capacity, namely base, monotonicity and normalization, which can be represented as follows:

$$
\begin{gathered}
m(\varnothing)=0 \\
\left\{\begin{array}{c}
m\left(\left\{g_{i}\right\}\right) \geq 0 \\
m\left(\left\{g_{i}\right\}\right)+\sum_{g_{i} \in T} m\left(\left\{g_{i}, g_{j}\right\}\right) \geq 0 \text { for all } g_{i} \in G \text { and } \emptyset \neq T \subseteq G \backslash\left\{g_{i}\right\}
\end{array}\right.
\end{gathered}
$$


And

$$
\sum_{g_{i} \in G} m\left(\left\{g_{i}\right\}\right)+\sum_{\left\{g_{i}, g_{j}\right\}} m\left(\left\{g_{i}, g_{j}\right\}\right)=1
$$

Thus, we can compute the Choquet integral as follows:

$$
C_{\mu}(a)=\sum_{g_{i} \in G} m\left(\left\{g_{i}\right\}\right) g_{i}(a)+\sum_{\left\{g_{i}, g_{j}\right\} \subseteq G} m\left(\left\{g_{i}, g_{j}\right\}\right) \min \left\{g_{i}(a), g_{j}(a)\right\}
$$

In this context, the two equations, which give the Shapley value of an indicator and a pair of interaction indicators respectively, can be expressed simply as follows (Silvia et al., 2018):

$$
\begin{gathered}
\varphi\left(\left\{g_{i}\right\}\right)=m\left(\left\{g_{i}\right\}\right)+\sum_{g_{i} \in G \backslash\left\{g_{i}\right\}} \frac{m\left(\left\{g_{i}, g_{j}\right\}\right)}{2} \\
\varphi\left(\left\{g_{i}, g_{j}\right\}\right)=m\left(\left\{g_{i}, g_{j}\right\}\right.
\end{gathered}
$$

NAROR belongs to the family of ROR methods (Corrente et al., 2017). It can provide preference information, based on two complexity levels: comparing alternatives and preference intensities to each other. It differs from other ROR methods as the DM in NAROR is able to give some preference information about the criteria $g_{i}, g_{j}, g_{l}, g_{k} \in G$. In particular, the indicator $\mathrm{g}_{\mathrm{i}}$ is more important than $\mathrm{g}_{\mathrm{j}}\left(g_{i}>g_{j} ; \varphi\left(\left\{g_{i}\right\}\right) \geq \varphi\left(\left\{g_{j}\right\}\right)+\varepsilon\right)$; indicators $\mathrm{g}_{\mathrm{i}}$ and $\mathrm{g}_{\mathrm{j}}$ are indifferent $\left(g_{i} \sim g_{j} ; \varphi\left(\left\{g_{i}\right\}\right)=\right.$ $\left.\varphi\left(\left\{g_{j}\right\}\right)\right)$; there is a positive or negative interaction between $\mathrm{g}_{\mathrm{i}}$ and $\mathrm{g}_{\mathrm{j}}\left(\varphi\left(\left\{g_{i}, g_{j} \geq \varepsilon(\leq-\varepsilon)\right\}\right)\right)$; indicator $\mathrm{g}_{\mathrm{i}}$ is preferred to $\mathrm{g}_{\mathrm{j}}$ more than $\mathrm{g}_{1}$ is preferred to $\mathrm{g}_{\mathrm{k}}\left(\left(g_{i}, g_{j}\right)>\left(g_{l}, g_{k}\right) ; \varphi\left(\left\{g_{i}\right\}\right)-\right.$ $\left.\varphi\left(\left\{g_{j}\right\}\right) \geq \varphi\left(\left\{g_{l}\right\}\right)-\varphi\left(\left\{g_{k}\right\}\right)+\varepsilon, \varphi\left(\left\{g_{l}\right\}\right) \geq \varphi\left(\left\{g_{k}\right\}\right)+\varepsilon\right)$; the important difference between $g_{i}$ and $\mathrm{g}_{\mathrm{j}}$ is the same as that between $\mathrm{g}_{\mathrm{l}}$ and $\mathrm{g}_{\mathrm{k}}$. Regarding the above conditions, $\varepsilon$ is an auxiliary variable, which is a small positive number used to transform strict inequality into weak inequality. The NAROR output is a necessary and a possible preference, which is made up of a pair of preference relationships $\left(\succsim^{N}, \gtrsim^{P}\right)$. $\gtrsim^{N}$ and $\gtrsim^{P}$ are the necessary preference and the possible preference respectively, and for each $a, b \in A$, they have to meet the following conditions:

$$
a \gtrsim^{N} \quad b \stackrel{\text { def }}{\Leftrightarrow} C_{\mu}(a) \geq C_{\mu}(b) \text { for all compatible abilities, }
$$

And

$$
a \gtrsim^{P} b \stackrel{\text { def }}{\Leftrightarrow} C_{\mu}(a) \geq C_{\mu}(b) \text { for at least one compatible ability }
$$


Compatible ability reflects a set of Möbius measures, and the preference information offered by the DM is restored. In addition, a linear programming method can be employed to check for the existence of compatible abilities, that is:

$$
\varepsilon^{*}=\max \varepsilon, \text { limited to } \xi^{D M}
$$

If $\xi^{D M}>0$ and $\xi^{D M}$ is feasible, this means that there is at least one compatible ability. Otherwise, there would be inconsistencies in the preferences given by the DM. If there is at least one compatible ability, then the following constraints set can be used to calculate the necessary and possible preferences:

$$
\xi^{N}(a, b): C_{\mu}(b) \geq C_{\mu}(a)+\varepsilon \text { and } \xi^{D M} ; \xi^{P}(a, b): C_{\mu}(a) \geq C_{\mu}(b) \text { and } \xi^{D M}
$$

We now turn to explaining SMAA. In the process of a value function and an outranking relationship, we need to compute the following parameters: the G capacity of the Choquet integral preference model, and the preference, indifference and veto thresholds for the outranking method (Roy, 1996). SMAA belongs to the MCDA family, and it can be used to consider the imprecision and/or uncertainty of the alternative assessments and the preference parameters. By regarding value functions and outranking relationships as a preferred model, SMAA methods can be employed to examine choice, ranking and sorting issues (Tervonen and Figueira, 2008). One such SMAA method, known as SMAA-2, is able to process ranking issues and contains a value function to indicate its underlying preference model (Lahdelma and Salminen, 2001). The value function for every alternative is the weighted average of all criteria for its numerical evaluation. Therefore, for every $a_{k} \in A$, we can obtain the following:

$$
U\left(a_{k}, w\right)=\sum_{i=1}^{n} w_{i} g_{i}\left(a_{k}\right)
$$

Where, $w \in W=\left\{\left(w_{1}, \ldots, w_{n} \in\left[R^{n}: w_{i} \geq 0\right.\right.\right.$ and $\left.\left.\sum_{i=1}^{n} w_{i}=1\right)\right\}$ is the vector of the index weights. We can then calculate the ranking position of the alternative using the following function:

$$
\operatorname{rank}(k, \xi, w)=1+\sum_{h \neq k} \rho\left(U\left(\xi_{h}, w\right)>U\left(\xi_{h}, w\right)\right)
$$

Where $\rho($ True $)=1$ and $\rho($ False $)=1$. In addition, based on $\xi \in \chi$, SMAA-2 is employed to calculate the set of indicator weights where $a_{k}$ ranks the $s$. For each $s \in\{1,2, \ldots,|A|\}$, the following formula can be used:

$$
W_{k}^{s}(\xi)=\{w \in W: \operatorname{rank}(k, \xi, w)=s\}
$$

In order to consider the possible rankings plurality and obtain robust recommendations, the following indices are also calculated using SMAA-2: 
And

$$
\text { Pairwise winning index: } p\left(a_{h}, a_{k}\right)=\int_{w \in W} f_{W}(w) \int_{\xi \in \chi: U\left(\xi_{h}, w\right)>U\left(\xi_{h}, w\right)} f_{\chi}(\xi) d \xi d w \text { (30) }
$$

Where, $b^{s}\left(a_{k}\right)$ indicates the probability that the alternative $a_{k}$ ranks $s ; p\left(a_{h}, a_{k}\right)$ denotes the probability that the alternative $a_{h}$ is preferred to $a_{k}$. Based on a computational view, the multidimensional integrals for the aforementioned two indices are estimated by employing a Monte Carlo approach.

We now introduce the MCHP and the Choquet integral preference model. The MCHP shows that the assessment indicators are not on the same level, but are structured hierarchically. Therefore, there is a root index at zero levels, and a set of sub-indices at the first level, and so on. The indicators at the lowest level are elementary (Figure 2).

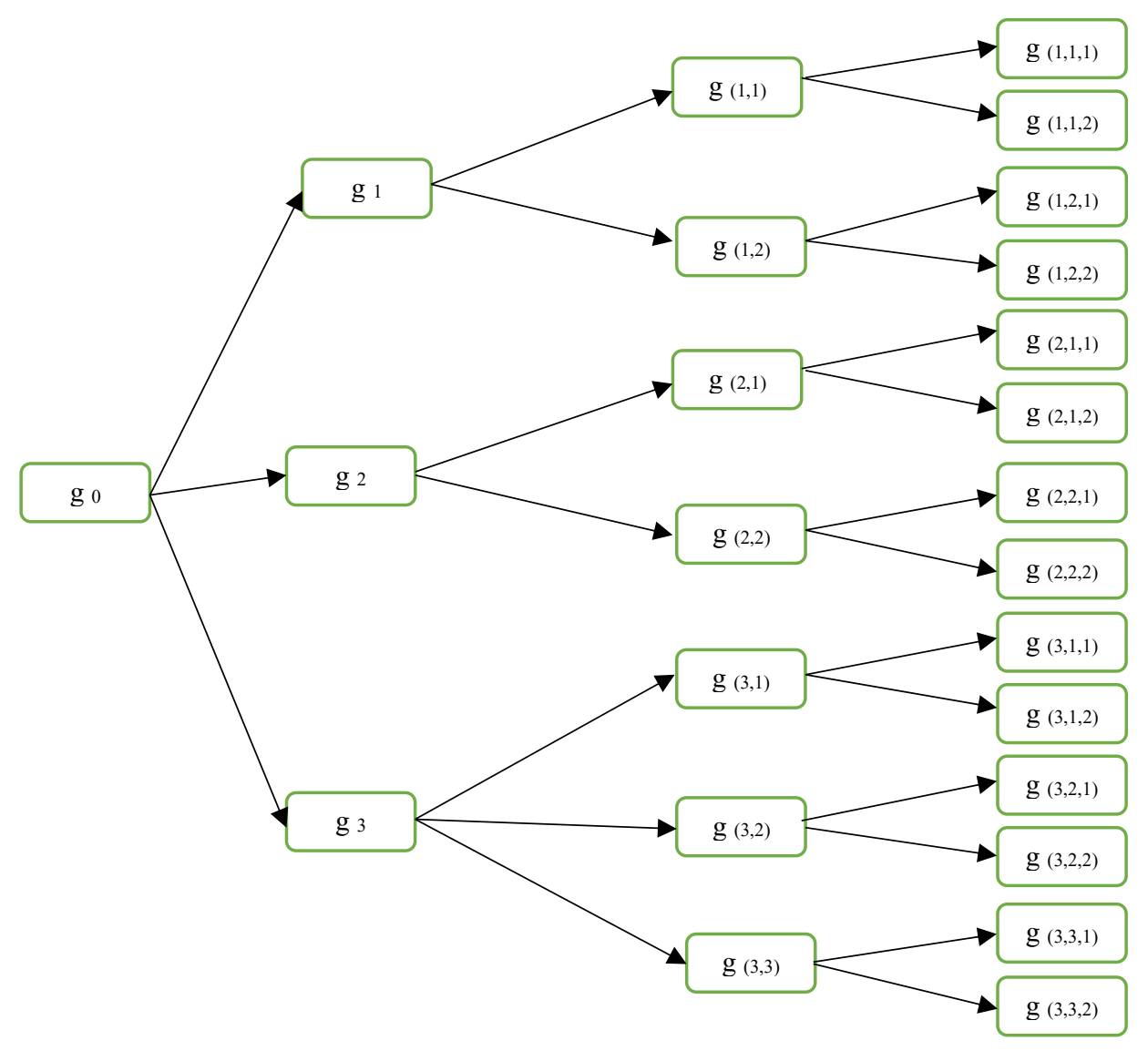

Figure 2. A hierarchy of indices displayed on three levels. 
In Figure 2, the indices set of elementary indicators: $E_{G}=$ $\{(1,1,1), \ldots,(3,3,2)\} ; g_{(1,1)}$ and $g_{(1,2)}$ give the immediate sub-indicators of $g_{1}$. The calculation of the Choquet integral is based on $\mu_{r}$. The following equation is employed to define $\mu_{r}$ :

$$
\mu_{r}(F)=\frac{\mu\left(\left\{g_{t}: t \in E(F)\right\}\right)}{\mu\left(\left\{g_{t}: t \in E\left(g_{r}\right)\right\}\right)}
$$

Where, $g_{r} \in G ; \mu\left(\left\{g_{t}: t \in E\left(g_{r}\right)\right\}\right) \neq 0 ; F \subseteq\left\{g_{(r, 1)}, \ldots, g_{(r, n(r))}\right\}$. Thus, the Choquet integral of $a$ on $g_{r}$ can be obtained by the following formula:

$$
C_{\mu_{r}}(a)=\frac{C_{\mu}\left(a_{r}\right)}{\mu\left(\left\{g_{t}: t \in E\left(g_{r}\right)\right\}\right)}
$$

$a_{r}$ refers to a fictitious alternative, and it has the same assessment as $a$ on the elementary indicators in $E\left(g_{r}\right)$. In addition, the null assessment on the elementary indicators is outside of $E\left(g_{r}\right)$. Thus, a preference relation to every non-elementary node $g_{r}$ can be obtained by the equation below:

$$
a \gtrsim_{r} b \stackrel{\text { def }}{\Leftrightarrow} C_{\mu_{r}}(a) \geq C_{\mu_{r}}(b) ; a, b \in A
$$

Angilella et al. (2016) provided a detailed description of how to apply the Choquet integral preference model to the setting of hierarchically structured indicators.

Lastly, we explain how ROR and SMAA are incorporated into the hierarchical Choquet integral preference model, in other words, the hierarchical-SMAA-Choquet integral method. The first step is to compute the Möbius representation of an ability, which is the powerset of the elementary indicators set. Regarding the special case with a 2-additive ability, the $m\left(\left\{g_{t}\right\}\right)$ to each elementary indicator $g_{t}$, and the $m\left(\left\{g_{t_{1}}, g_{t_{2}}\right\}\right)$ to each unordered pair of elementary indicators $\left\{g_{t_{1}}, g_{t_{2}}\right\}$, have to be determined. An ordinal regression is employed to calculate these values, which is based on providing appropriately indirect preference information. Silvia et al. (2018) explained this technique in detail. Using this method, the indices of the rank acceptability index and pairwise winning index can be computed by the SMAA methodology. Furthermore, we can also calculate the following indices by taking advantage of the rank acceptability indices:

$$
\text { Downward cumulative rank acceptability index } b_{r}^{\leq s}\left(a_{k}\right)=\sum_{q=1}^{s} b_{r}^{q}\left(a_{k}\right)
$$

And

Upward cumulative rank acceptability index $b_{r}^{\geq s}\left(a_{k}\right)=\sum_{q=s}^{|A|} b_{r}^{q}\left(a_{k}\right)$ 
$b_{r}^{\leq S}\left(a_{k}\right)$ denotes the $a_{k}$ frequency which is not greater than s.w.r.t; $b_{r}^{\geq s}\left(a_{k}\right)$ refers to the frequency which is also not lower than the aforementioned. Finally, at a comprehensive level, we can obtain Nap-preference and SMAA indices, that is the root indicator $g_{0}$.

\section{Results and findings}

Based on the discussion in the methodology section, the entire hierarchy of indicators is shown in Figure 3. The application of the Choquet integral requires all assessment indicators to be expressed using the same scale. Thus, we generally conduct the normalisation procedure before offering a proposed methodology. In our indicator selection, we processed these indicators by normalisation. However, the results of applying NAROR at the integrated level and each macro standard (i.e. social, economic and environmental) are not sufficient to fully capture our decision-making problems (Silvia et al., 2018). In addition to the weak advantage relationship, using the NAROR adds only a few new pairs to the necessary preference relationship at the comprehensive level and macro standards. Therefore, in order to better understand the case studies being reviewed, the study implemented the SMAA. First, we calculated the best and worst positions that each province can achieve. To this end, the study considered the full set of capabilities that are appropriate to the preferences provided by the decision-makers, and the three grades that represent the highest-level acceptability index (i.e. the three most frequent positions occupied by that province). In order to compare different provinces, we considered the reference ranking of Environment, because this macro standard is the most important according to the evaluation of the DM. The provinces are ranked according to the position of their highest-ranking acceptability indicator. In the first positions are those provinces which show the highest-ranking acceptability indicator for the first positions. For example, in Table 2 (3), according to the environment macro-criterion, the study presents the three highest-ranking acceptability indices, and the best and the worst positions for the first seven and last three provinces with respect to their considered ranking.

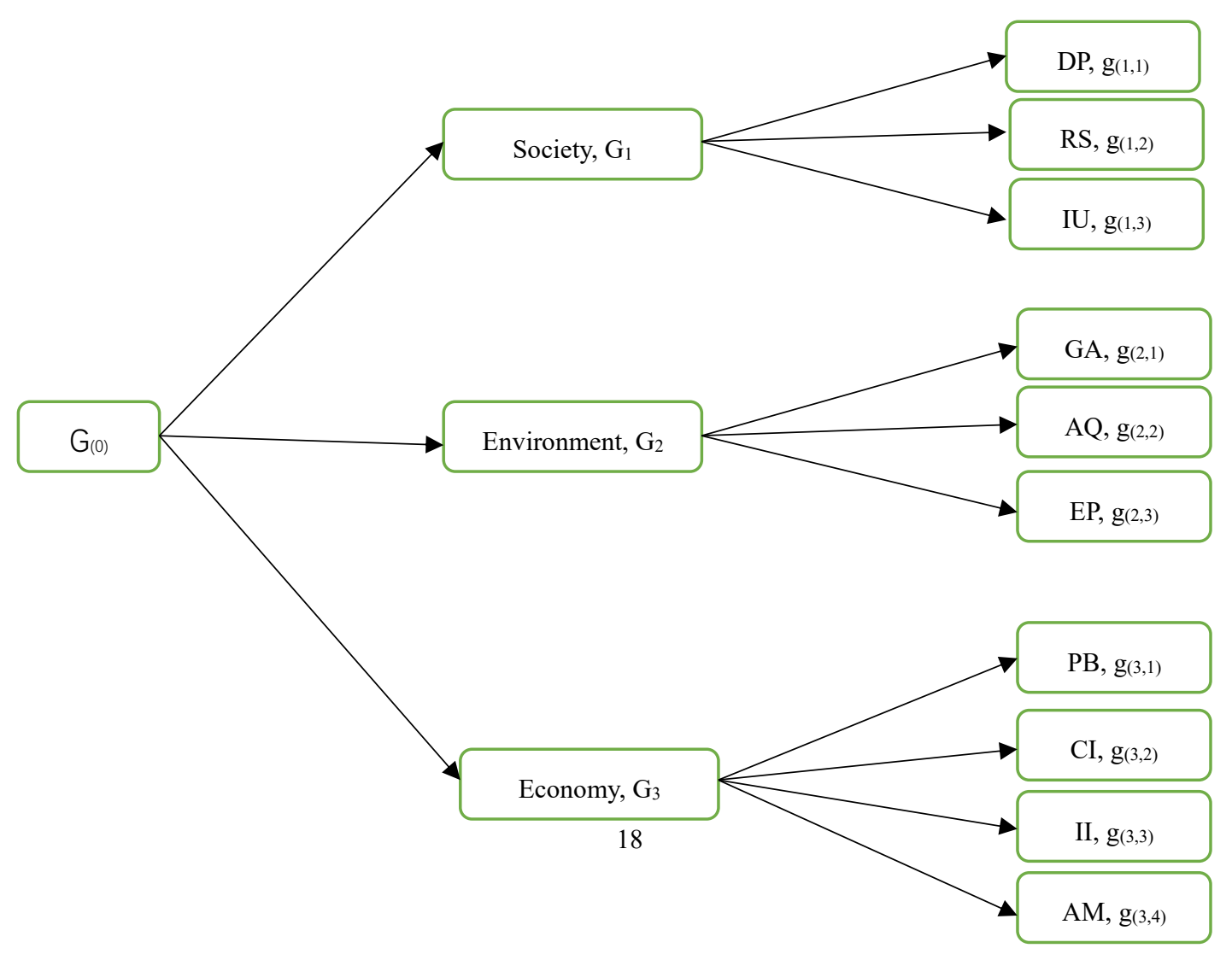


Figure 3 The hierarchy of indicators.

First, we focus on Table 2 (3) because Environment is the most relevant and important indicator in the evaluation of the urbanization bubble. According to Table 2 (3), a $a_{31}$ (Zhejiang) has the most serious urbanization bubble, because its ranking acceptability indicator of first position is $99.71 \%$. Due to rapid urban sprawl, a significant Urban Heat Island effect exists in Zhejiang, while urbanisation has also led to hot degree days and additional hot days in urban areas (Yang etal., 2014). Moreover, urbanisation has placed a heavy burden on regional and local air quality in Zhejiang, resulting in serious environmental problems at both the city and regional levels (Yang etal., 2014; Chen, Yang and Zhu, 2014). a 16 (Jiangsu), a (Guangdong) and a4 (Fujian) also appear to have significant urbanisation bubbles, since they have high ranking acceptability indices in the first ranking positions, and their position intervals are [2,5], [2,6] and [2,6], respectively. Although significant progress has been made in the sustainable urbanisation of coastal areas in social terms, this has not been accompanied by a similar improvement in relation to the environment (Liu et al., 2013). In China's Eastern Coastal regions, economic growth and the rapid expansion of the urban population are regarded as significant factors in stimulating the urban expansion process, but highly efficient use of urban land does not take land resource preservation into consideration ( $\mathrm{Li}$ et al., 2014). In addition, the literature indicates that soil landscapes are dispersed and fragmented in their distribution, and thus the permanent loss and increasing fragmentation of soil landscape patterns and valuable soil resources poses a threat to sustainable urbanisation in Eastern China (Li et al., 2015). In addition, the last three provinces show the highest-ranking acceptability indices with respect to the lowest positions. In particular, $\mathrm{a}_{29}$ (Uygur Autonomous Region) frequently occupies positions 30 or 31, and it is one of the two lowest-ranked provinces in all cases. Meanwhile, the highest-ranking acceptability indicator for $\mathrm{a}_{20}$ (Ningxia Hui Autonomous Region) is 29.99\%, and its best position is 24th. Lastly, $\mathrm{a}_{28}$ (Tibet Autonomous Region) is the province with the highestranking acceptability for the last position (31.27\%). Its second and third highest-ranking acceptability indices occupy 31 st and $26^{\text {th }}$ positions, respectively. The best position it achieves is 30th, although the ranking acceptability indicator for this position is 0 . Overall, due to a high degree of socio-economic exclusion and an increasing income gap, China's Western regions are experiencing a slow urbanisation process, and compared with the previous urban development, the drawbacks of urbanisation for this area have not been clearly highlighted (Cao, 2010). However, the Chinese government plans to use market-based instruments to promote the development of the western region, in a way that protects its fragile ecological systems and environment. Accelerating sustainable urbanisation is viewed as a potential means of encouraging western development (Deng and Bai, 2014).

Second, the study discusses the rankings of the other three cases. Table 2 (2) is computed using the Society macro-criterion. Unlike for the Environment macro-criterion, $\mathrm{a}_{31}$ (Zhejiang) is unstable with respect to the Society macro-criterion, since its highest-ranking acceptability indicator is very low (2.13\%), meaning that Zhejiang's social bubble is only minor. Zhejiang's urban development not only benefits from economic factors, but is also based on a wide range of continuous movements of political and local restructuring from the bottom up, which has fostered a new social and political dynamism both at local and national levels (Bernard and Shi, 2011). By contrast, a4 (Fujian) is stable 
in economic terms, because its three highest-ranking acceptability indices are those corresponding to the $5^{\text {th }}$ and $6^{\text {th }}$ positions. Chen (2006) suggested that because it has had to find a way to transform a low-value-added economy, urbanisation in Fujian is impacted by non-agricultural employment and industrialisation. By managing to resolve the imbalance and lack of coordination within economy, Fujian has avoided many of the economic events that threaten sustainable urbanisation (Luo et al., 2018). In addition, $a_{16}$ (Jiangsu) can be regarded as having a significant social bubble, because the positions of its three highest-ranking acceptability indices range from $2^{\text {nd }}$ to $4^{\text {th }}$. Capital and power have played a significant role in promoting the rapid development and growth urbanisation, but the gap between regions and the inequalities in incomes between urban and rural areas in Jiangsu province have not been correspondingly reduced, which has led to a number of potential social risks and spatial inequalities (Ye et al., 2017). Moreover, residents tend not to form close social relationships with each other and social interaction is not very dynamic in Jiangsu province (Wu et al., 2019). The range of the best and worst positions is relatively small, being within the interval $[4,6]$. Finally, $\mathrm{a}_{23}$ (Shanghai) ranks relatively high for the Environment macro-criterion, whereas it ranks relatively low in relation to Society, meaning that Shanghai has a higher level of welfare. Turning to the last three provinces, compared to the Environment macro criterion, the positions of $\mathrm{a}_{20}, \mathrm{a}_{28}$ and $\mathrm{a}_{29}$ have improved with respect to the Society bubble, though they still occupy the lowest positions.

We then analysed the same provinces against the Economy macro criterion. According to Table 2 (4), $\mathrm{a}_{6}$ (Guangdong) has the most serious economic bubble out of the first seven provinces considered, since the positions of its highest-ranking acceptability indices range from 5th to 8th. Moreover, the province's best position is $2^{\text {nd }}$, albeit with a negligible frequency, and its worst position is 21 st with a frequency of $0.16 \%$. $\mathrm{a}_{16}$ is relatively stable as none of its highest-ranking acceptability positions are lower than 12, indicating that Guangzhou has experienced a serious economic bubble in the process of urbanization. Regarding the last three provinces in Table 2 (4), none of their positions have improved. In addition, although $\mathrm{a}_{20}$ 's and $\mathrm{a}_{28}$ 's highest positions are 21 and 20 respectively, they are frequently located in the bottom section of the rankings. Thus, none of these three provinces has a serious economic bubble.

Finally, we explain Table 2 (1), which is based on the comprehensive level. According to Table 2 (1), the best two provinces are $a_{31}$ and $a_{4}$ because they achieved the three highest-ranking acceptability indices in the first three positions, indicating that Zhejiang and Fujian have experienced serious urbanisation bubbles. In addition, the position of $\mathrm{a}_{4}$ can be located at the top of the rankings, since its worst position is $10^{\text {th }}$, compared to $\mathrm{a}_{31}$ 's $16^{\text {th }}$. Meanwhile, a 6 is ranked $3 \mathrm{rd}$ as its most frequent positions are 2, 3 and 4 with frequencies of $45.33 \%, 41.08 \%$ and $24.96 \%$, respectively. Regarding the last three provinces, compared with their rankings for the Environment macro-criterion, their positions at the comprehensive level have only improved slightly. Furthermore, these three provinces achieved their highest-ranking acceptability indices with respect to the lowest positions in this ranking. In addition, a 29 is placed 31 st (last position) with a highestranking acceptability of $89.37 \%$. The other two provinces are placed at the bottom of the worst ranking provinces, in particular $\mathrm{a}_{20}$ with a frequency of $13.71 \%$.

Table 2 Highest ranking acceptability indices, as well as the best and worst positions for the ranked provinces in 
China, based on comprehensive level (1), society (2), environment (3) and economy (4)

\begin{tabular}{|c|c|c|c|c|c|c|c|c|c|c|}
\hline \multicolumn{11}{|c|}{ (1) Comprehensive level } \\
\hline Province & $h_{i g h}$ & $b_{0}^{\text {high }_{1}}(\cdot)(\%)$ & $h_{i g h}$ & $b_{0}^{\text {high }_{2}}(\cdot)(\%)$ & $\mathrm{high}_{3}$ & $b_{0}^{\text {high }_{3}}(\cdot)(\%)$ & Best & $b_{0}^{\text {Best }}(\cdot)(\%)$ & Worst & $b_{0}^{\text {Worst }}(\cdot)(\%)$ \\
\hline a31 & 1 & 18.28 & 1 & 31.19 & 2 & 13.29 & 1 & 31.26 & 16 & 0.00 \\
\hline a4 & 3 & 43.71 & 2 & 25.23 & 3 & 18.91 & 1 & 24.28 & 10 & 0.00 \\
\hline a6 & 2 & 45.33 & 4 & 41.08 & 3 & 24.96 & 3 & 0.33 & 9 & 0.00 \\
\hline a16 & 6 & 19.84 & 5 & 38.13 & 6 & 21.22 & 3 & 0.01 & 13 & 0.01 \\
\hline a9 & 9 & 32.11 & 12 & 19.99 & 7 & 17.73 & 4 & 0.00 & 11 & 0.00 \\
\hline $\mathrm{a} 26$ & 8 & 28.07 & 9 & 15.43 & 7 & 16.72 & 2 & 0.03 & 15 & 0.03 \\
\hline $\mathrm{a} 23$ & 11 & 16.99 & 10 & 26.62 & 12 & 14.13 & 7 & 0.00 & 17 & 0.00 \\
\hline$\vdots$ & $\vdots$ & $\vdots$ & $\vdots$ & $\vdots$ & $\vdots$ & $\vdots$ & $\vdots$ & $\vdots$ & $\vdots$ & $\vdots$ \\
\hline a20 & 28 & 39.88 & 27 & 24.31 & 30 & 43.32 & 26 & 0.00 & 30 & 13.71 \\
\hline a28 & 25 & 43.21 & 28 & 20.05 & 29 & 9.06 & 27 & 0.01 & 30 & 0.23 \\
\hline a29 & 31 & 89.37 & 30 & 20.33 & 31 & 15.55 & 29 & 0.00 & 29 & 21.42 \\
\hline \multicolumn{11}{|c|}{ (2) Society } \\
\hline Province & high $_{1}$ & $b_{1}^{\text {high }}(\cdot)(\%)$ & high $_{2}$ & $b_{1}^{\text {high }_{2}}(\cdot)(\%)$ & $h_{i g h}$ & $b_{1}^{\text {high }_{3}}(\cdot)(\%)$ & Best & $b_{1}^{\text {Best }}(\cdot)(\%)$ & Worst & $b_{1}^{\text {Worst }}(\cdot)(\%)$ \\
\hline a31 & 3 & 2.13 & 7 & 18.19 & 5 & 18.27 & 2 & 0.02 & 8 & 0.00 \\
\hline a4 & 5 & 19.04 & 5 & 14.26 & 6 & 16.51 & 1 & 7.23 & 9 & 0.00 \\
\hline a6 & 4 & 8.20 & 9 & 31.07 & 5 & 11.39 & 4 & 0.00 & 11 & 2.11 \\
\hline a16 & 2 & 7.12 & 4 & 18.29 & 3 & 8.99 & 4 & 0.00 & 6 & 0.00 \\
\hline a9 & 7 & 11.46 & 5 & 22.01 & 7 & 20.38 & 3 & 0.01 & 7 & 0.01 \\
\hline a26 & 6 & 51.37 & 3 & 31.18 & 8 & 17.32 & 5 & 11.21 & 12 & 0.00 \\
\hline a23 & 18 & 2.98 & 5 & 9.92 & 11 & 9.66 & 7 & 18.19 & 5 & 4.25 \\
\hline$\vdots$ & $\vdots$ & $\vdots$ & $\vdots$ & $\vdots$ & $\vdots$ & & $\vdots$ & & $\vdots$ & $\vdots$ \\
\hline $\mathrm{a} 20$ & 20 & 28.77 & 22 & 27.31 & 19 & 41.01 & 28 & 24.12 & 19 & 0.01 \\
\hline $\mathrm{a} 28$ & 23 & 21.06 & 20 & 23.19 & 20 & 34.29 & 26 & 0.00 & 23 & 0.03 \\
\hline a29 & 26 & 33.15 & 28 & 30.63 & 24 & 31.77 & 30 & 0.03 & 29 & 0.00 \\
\hline \multicolumn{11}{|c|}{ (3) Environment } \\
\hline Province & high $_{1}$ & $b_{2}^{\text {high }_{1}}(\cdot)(\%)$ & $h_{i g h}$ & $b_{2}^{\text {high }_{2}}(\cdot)(\%)$ & $h_{i g h}$ & $b_{2}^{\text {high }_{3}}(\cdot)(\%)$ & Best & $b_{2}^{\text {Best }}(\cdot)(\%)$ & Worst & $b_{2}^{\text {Worst }}(\cdot)(\%)$ \\
\hline a31 & 1 & 99.71 & & & & & 1 & 100.00 & 1 & 100.00 \\
\hline a4 & 2 & 98.92 & 4 & 2.08 & 6 & 0.07 & 3 & 98.31 & 6 & 0.00 \\
\hline a6 & 3 & 97.47 & 5 & 3.12 & 6 & 0.16 & 2 & 99.82 & 4 & 0.00 \\
\hline a16 & 4 & 94.56 & 3 & 1.21 & 5 & 1.27 & 2 & 0.75 & 3 & 0.00 \\
\hline a9 & 5 & 96.88 & 3 & 1.22 & 5 & 1.94 & 4 & 1.24 & 11 & 0.00 \\
\hline a26 & 6 & 92.31 & 6 & 4.33 & 5 & 2.11 & 5 & 0.86 & 9 & 0.00 \\
\hline $\mathrm{a} 23$ & 7 & 89.64 & 8 & 6.91 & 8 & 0.95 & 3 & 0.00 & 8 & 0.01 \\
\hline$\vdots$ & $\vdots$ & $\vdots$ & $\vdots$ & : & $\vdots$ & $\vdots$ & $\vdots$ & $\vdots$ & $\vdots$ & $\vdots$ \\
\hline $\mathrm{a} 20$ & 29 & 29.99 & 28 & 34.31 & 24 & 18.16 & 29 & 0.01 & 27 & 11.21 \\
\hline $\mathrm{a} 28$ & 30 & 31.27 & 31 & 36.12 & 26 & 15.21 & 30 & 0.00 & 30 & 3.03 \\
\hline a29 & 31 & 25.69 & 27 & 33.50 & 28 & 9.03 & 31 & 0.02 & 30 & 72.13 \\
\hline \multicolumn{11}{|c|}{ (4) Economy } \\
\hline Province & $h_{i g h}$ & $b_{3}^{h i g h_{1}}(\cdot)(\%)$ & high $_{2}$ & $b_{3}^{\text {high }_{2}}(\cdot)(\%)$ & $h_{i g h}$ & $b_{3}^{\text {high }_{3}}(\cdot)(\%)$ & Best & $b_{3}^{\text {Best }}(\cdot)(\%)$ & Worst & $b_{3}^{\text {Worst }}(\cdot)(\%)$ \\
\hline
\end{tabular}




\begin{tabular}{|c|c|c|c|c|c|c|c|c|c|c|}
\hline a31 & 16 & 15.38 & 19 & 14.29 & 14 & 12.19 & 3 & 0.00 & 25 & 0.00 \\
\hline $\mathrm{a} 4$ & 13 & 21.03 & 12 & 27.13 & 11 & 17.64 & 6 & 0.01 & 19 & 0.07 \\
\hline a6 & 5 & 28.77 & 6 & 16.52 & 8 & 8.79 & 2 & 2.13 & 21 & 0.16 \\
\hline a16 & 9 & 29.91 & 10 & 21.18 & 6 & 12.17 & 4 & 0.00 & 16 & 0.00 \\
\hline a9 & 21 & 9.75 & 17 & 9.78 & 15 & 9.46 & 9 & 0.02 & 18 & 0.05 \\
\hline a26 & 18 & 11.34 & 20 & 11.29 & 19 & 7.04 & 5 & 1.11 & 14 & 0.00 \\
\hline $\mathrm{a} 23$ & 15 & 27.11 & 14 & 18.22 & 18 & 24.31 & 11 & 0.03 & 9 & 0.01 \\
\hline$\vdots$ & $\vdots$ & $\vdots$ & $\vdots$ & $\vdots$ & $\vdots$ & $\vdots$ & $\vdots$ & $\vdots$ & $\vdots$ & $\vdots$ \\
\hline $\mathrm{a} 20$ & 25 & 18.06 & 27 & 12.19 & 30 & 14.27 & 21 & 0.00 & 22 & 0.21 \\
\hline a28 & 27 & 20.22 & 31 & 10.33 & 26 & 11.33 & 25 & 0.00 & 20 & 0.03 \\
\hline a29 & 30 & 23.17 & 29 & 15.42 & 28 & 17.08 & 28 & 13.01 & 31 & 0.00 \\
\hline
\end{tabular}

Table 3 shows the barycenter of compatible capacities Möbius representation with the preferences obtained by the DM. These results can help us to understand the provinces' rankings at the Social bubble level, Environment bubble level, Economic bubble level and comprehensive level. Without taking the interaction between the indicators into account, we can see that the three most important indices come under the Environment macro-criterion, i.e., GA (0.1912) > EP (0.1451) > AQ (0.1076). In addition to the preference information provided by the DM, Table 3 also gives information about the positive and negative interaction between indicators. For example, the interaction between DP and II is negative, whereas the interaction between DP and AQ is positive.

Table 3 The barycenter of compatible capacities Möbius representation

\begin{tabular}{|c|l|l|l|l|l|l|l|l|l|}
\hline$m(\{D P\})$ & 0.0312 & $m(\{R S\})$ & 0.0367 & $m(\{I U\})$ & 0.0132 & $m(\{G A\})$ & 0.1912 & $m(\{A Q\})$ & 0.1076 \\
\hline$m(\{E P\})$ & 0.1451 & $m(\{P B\})$ & 0.0378 & $m(\{C I\})$ & 0.0211 & $m(\{I I\})$ & 0.0853 & $m(\{A M\})$ & 0.0742 \\
\hline$m(\{D P, R S\})$ & 0.0002 & $m(\{D P, I U\})$ & -0.0001 & $m(\{D P, G A\})$ & 0.0003 & $m(\{D P, A Q\})$ & 0.0005 & $m(\{D P, E P\})$ & -0.0002 \\
\hline$m(\{D P, P B\})$ & 0.0007 & $m(\{D P, C I\})$ & 0.0003 & $m(\{D P, I I\})$ & -0.0004 & $m(\{D P, A M\})$ & 0.0006 & $m(\{\mathrm{RS}, \mathrm{IU}\})$ & -0.0005 \\
\hline$m(\{\mathrm{RS}, \mathrm{GA}\})$ & 0.0001 & $m(\{\mathrm{RS}, \mathrm{AQ}\})$ & 0.0004 & $m(\{\mathrm{RS}, \mathrm{EP}\})$ & -0.0003 & $m(\{R S, P B\})$ & 0.0007 & $m(\{R S, C I\})$ & 0.0010 \\
\hline$m(\{R S, I I\})$ & 0.0011 & $m(\{R S, A M\})$ & 0.0002 & $m(\{I U, G A\})$ & 0.0007 & $m(\{I U, A Q\})$ & -0.0013 & $m(\{I U, E P\})$ & 0.0005 \\
\hline$m(\{I U, P B\})$ & 0.0007 & $m(\{I U, C I\})$ & -0.0002 & $m(\{I U, I I\})$ & -0.0012 & $m(\{I U, A M\})$ & 0.0008 & $m(\{G A, A Q\})$ & -0.0006 \\
\hline$m(\{G A, E P\})$ & -0.0121 & $m(\{G A, P B\})$ & 0.0017 & $m(\{G A, C I\})$ & 0.0015 & $m(\{G A, I I\})$ & 0.0009 & $m(\{G A, A M\})$ & 0.0014 \\
\hline$m(\{A Q, E P\})$ & 0.0001 & $m(\{A Q, P B\})$ & 0.0021 & $m(\{A Q, C I\})$ & -0.0000 & $m(\{A Q, I I\})$ & 0.0013 & $m(\{A Q . A M\})$ & -0.0003 \\
\hline$m(\{E P, P B\})$ & 0.0024 & $m(\{\mathrm{EP}, \mathrm{CI}\})$ & 0.0011 & $m(\{\mathrm{EP}, \mathrm{II}\})$ & -0.0031 & $m(\{E P, A M\})$ & 0.0007 & $m(\{P B, C I\})$ & -0.0008 \\
\hline$m(\{P B, I I\})$ & 0.0003 & $m(\{P B, A M\})$ & -0.0010 & $m(\{C I, I I\})$ & 0.0009 & $m(\{C I, A M\})$ & 0.0011 & $m(\{I I, A M\})$ & 0.0004 \\
\hline
\end{tabular}

In order to rank the provinces at the macro-criteria level and comprehensive level, the study calculated the Choquet integral value of every province using the barycentre of compatible capacities Möbius representation. Table 4 depicts the positions of each province using Möbius representation. The results displayed in Table 4 indicate that the ranking of each province relies on the criterion used. For instance, in terms of Society and Economy, Zhejiang ranks $4^{\text {th }}$ and $12^{\text {th }}$, respectively, while it is ranked in $1^{\text {st }}$ place at the comprehensive level. These results reflect the advantages of the method we used, because it provides two different aspects of assessment of the urbanisation bubble, namely each node of the criteria hierarchy and a global level (Silvia et al., 2018). 
Table 4 Rank and corresponding Choquet value of each province

\begin{tabular}{|c|c|c|c|c|}
\hline \multirow[t]{2}{*}{ Province } & \multicolumn{4}{|l|}{ Rank (Choquet value) } \\
\hline & (1) Comprehensive level & (2) Society & (3) Environment & (4) Economy \\
\hline Zhejiang & $1(0.71)$ & $4(0.54)$ & $1(0.98)$ & $12(0.65)$ \\
\hline Fujian & $4(0.59)$ & $6(0.49)$ & $2(0.96)$ & $13(0.63)$ \\
\hline Guangdong & $3(0.63)$ & $2(0.61)$ & $3(0.91)$ & $7(0.71)$ \\
\hline Jiangsu & $6(0.52)$ & $8(0.38)$ & $4(0.89)$ & $9(0.68)$ \\
\hline Hainan & $9(0.45)$ & $5(0.51)$ & $5(0.82)$ & $18(0.52)$ \\
\hline Sichuan & $8(0.47)$ & $7(0.46)$ & $6(0.79)$ & $21(0.47)$ \\
\hline Shanghai & $11(0.41)$ & $14(0.25)$ & $7(0.73)$ & $14(0.58)$ \\
\hline$\vdots$ & $\vdots$ & $\vdots$ & $\vdots$ & $\vdots$ \\
\hline Ningxia Hui Autonomous Region & $28(0.21)$ & $21(0.19)$ & $29(0.33)$ & $26(0.35)$ \\
\hline Tibet Autonomous Region & $25(0.27)$ & $24(0.15)$ & $30(0.29)$ & $30(0.27)$ \\
\hline Uygur Autonomous Region & $31(0.17)$ & $28(0.11)$ & $31(0.20)$ & $31(0.20)$ \\
\hline
\end{tabular}

\section{Conclusions}

The study evaluated China's urbanisation bubble at the provincial level by proposing a hierarchicalSMAA-Choquet integral method to calculate composite indices. The method is able to aggregate the urbanisation bubble indices using the Choquet integral preference model and consider the interactions between various indicators. In addition, we applied ROR and SMAA to deal with the robustness issues associated with considering the entire set of weights assigned to the urbanisation bubble composite indicator. Furthermore, by employing MCHP, the study aggregated urbanisation bubble indices not only at the comprehensive level, but also at the intermediate levels of the hierarchy. It also considered spatial disparity by focusing on the measure at the provincial level.

It is important to evaluate China's urbanisation bubble effectively with respect to sustainability. The study findings showed that, overall, the ranking of urbanisation bubbles is positively related to the level of regional development. There is a high level of urbanization in Zhejiang, Fujian, Guangzhou and Jiangsu. On the contrary, in some less developed provinces, such as Uygur Autonomous Region, Tibet Autonomous Region, and Ningxia Hui Autonomous Region, the urbanisation bubble is not very obvious, which may be due to the low level and speed of urbanisation in these places. There are also some limitations which can be taken into consideration in further studies. First, although we presented the final results of China's urbanisation bubble by introducing an appropriate methodology, this study does not provide an in-depth analysis of the reasons for these results. Thus, future studies could explore the reasons for these rankings in more depth. Moreover, our methodology does not take spatial dependence into account. This is important because spatial dependence may change the weights of indicators in the urbanization bubble evaluation, and thus, future studies could try to include spatial effects within the hierarchical-SMAA-Choquet integral method.

The contributions of this research are threefold: first, to the best of our knowledge, an innovative 
approach, namely the SMAA Choquet integral method, was applied to evaluate the urbanisation bubble in China. Second, using the SMAA model enabled us to compare and evaluate a relatively large number of cities, namely 31 , whereas previous studies have assessed a much smaller number (Zhou et al., 2015; Zhang and Li, 2020). Third, although the SMAA-based model has been applied to real life situations, such as examining the Italian public health bill (De Matteis et a., 2019), providing decision-making support for centralising cargo at a Moroccan airport hub (Menou et al., 2010), and undertaking a market acceptability assessment of electric vehicles (Gong et al., 2020), it has not been used to assess a real-life urbanisation bubble within the field of sustainable urban studies. Therefore, our research adds value in this respect.

In terms of policy implications, our findings could help urban planners and policy makers to understand and identify which cities are more likely to experience urbanisation bubbles and thus apply a series of mitigating measures to tackle the resulting issues in order to direct them towards a more sustainable trajectory.

With regards to further research, the SMAA Choquet integral method is used in this research as a relatively innovative way of measuring and evaluating an urbanisation bubble in China. The next step/further research could compare the goodness-of-fit of the SMAA model with other potential or existing models used to assess urbanisation bubbles.

\section{Acknowledgements}

The authors would like to gratefully acknowledge the EPSRC for funding this work through its financial support (EPSRC Reference: EP/R035148/1). This research is also partly funded by the NSFC (Project No. 51808392), the SCUE Research Fund, and the School Funding from the University of Westminster. Thanks also to the editor Professor Cecília Maria Villas Bôas de Almeida and the anonymous reviewers for their valuable comments on the initial draft of this paper. 


\section{References}

Ahmad, F., Draz, M.U., Su, L., Ozturk, I., Rauf, A., 2018. Tourism and environmental pollution: Evidence from the one belt one road provinces of western China. Sustainability, 10, p. 3520.

Angilella, S., Corrente, S., Greco, S., 2012. SMAA-Choquet: Stochastic Multicriteria Acceptability Analysis for the Choquet Integral, in: S.G. et al. (Ed.), Advances in Computational Intelligence, of Communications in Computer and Information Science. Berlin: Springer, pp. 248-257.

Angilella, S., Corrente, S., Greco, Słowiński, R., 2016. Robust ordinal regression and stochastic multiobjective acceptability analysis in multiple criteria hierarchy process for the Choquet integral preference model. Omega. 63, pp. 154-169.

Angilella,S., Greco, S., Matarazzo, B., 2010. Non-additive robust ordinal regression: a multiple criteria decision model based on the Choquet integral. Eur. J. Oper. Res., 201 (1), pp. 277-288.

Bandura, R., 2008. A Survey of Composite Indices Measuring Country Performance: 2008, Update, New York: United Nations Development Programme, Office of Development Studies (UNDP/ODS Working Paper).

Bernard, G., \& Shi, L. 2011. Local economic development and transformations of the political discourse and practices in China: Case analyses from the Zhejiang region from the 1980s. European Journal of East Asian Studies, 10 (2), pp. 203-226.

Böhringer, C., Jochem, P.E.P., 2007. Measuring the immeasurable-A survey of sustainability indices. Ecol. Econ., 63 (1), pp. 1-8.

Cao, H. 2010. Urban-Rural Income Disparity and Urbanization: What Is the Role of Spatial Distribution of Ethnic Groups? A Case Study of Xinjiang Uyghur Autonomous Region in Western China. Regional Studies, 44 (8), 965-982.

Cao, M., Chen, C-L., Hickman, R., 2017. Transport emissions in Beijing: A scenario planning approach. Proceedings of the Institution of Civil Engineers - Transport, 170(2), pp. 65-75.

Caragliu, A., Del Bo, C., Nijkamp, P., 2011. Smart cities in Europe. J. Urban Technol., 18, pp. 65-82.

Chen, A. 2006. Urbanization in China and the case of Fujian province. Modern China, 32 (1), pp. 99-130.

Chen, J., 2007. Rapid urbanization in China: A real challenge to soil protection and food security. Catena, 69, pp. 1-15.

Chen, F., Yang, X., Zhu, W. 2014. WRF simulations of urban heat island under hot-weather synoptic conditions: The case study of Hangzhou City, China. Atmos. Res., 138, pp. 364-377.

Chen, M.X., 2015. Research progress and scientific issues in the field of urbanization. Geogr. Res., 34 (4), pp. 614630. (in Chinese)

Cinelli, M., Coles, S.R., Kirwan, K., 2014. Analysis of the potentials of multi criteria decision analysis methods to conduct sustainability assessment. Ecol. Indic., 46, pp. 138-148.

Cohen, M., 2017. A systematic review of urban sustainability assessment literature. Sustainability, 9, p. 2048.

Cornelissen, A.M.G., Berg, J.V.D., Koops,W.J ,Grossman, M., Udo, H.M.J., 2001. Assessment of the contribution of sustainability indicators to sustainable development: A novel approach using fuzzy set theory. Agric. Ecosyst. Environ., 86, pp. 173-185.

Corrente, S., Greco, S., Kadziński, M., Słowiński, R., 2013. Robust ordinal regression in preference learning and ranking. Mach. Learn., 93, pp. 381-422.

Corrente, S., Greco, S., Słowiński, R., 2016. Multiple criteria hierarchy process for Electre Tri methods. Eur. J. Oper. Res., 252 (1), pp. 191-203.

Croes, R., 2011. Measuring and explaining competitiveness in the context of small island destinations. Journal of Travel Research, 50(4), pp. 431-442. 
Dahl, A.L., 2012. Achievements and gaps in indicators for sustainability. Ecol. Indic., 17, pp. 14-19.

Deng, X., \& Bai, X., 2014. Sustainable Urbanization in Western China. Environment: Science and Policy for Sustainable Development, 56 (3), pp. 12-24.

Dong, M., Wu, D., Fu, X., Deng, H \& Wu, G. 2015. Regional-scale analysis on the strengths, weaknesses, opportunities, and threats in sustainable development of Shangri-La County. International Journal of Sustainable Development and World Ecology, 22 (2), pp. 171-177.

Dyson, T., 2011. The role of the demographic transition in the process of urbanization. Popul. Dev. Rev., 37, pp. 34 54.

Ejaro, S. P., Abubakar, A., 2013. The challenges of rapid urbanization on sustainable development of Nyanya, Federal Capital Territory, Abuja, Nigeria. Journal of Applied Sciences and Environmental Management, 17 (2), pp. 299-313.

Fang, C.L., Wang, Z.B., Xu, G., 2016. Spatial-temporal characteristics of PM2.5 in China: A city-level perspective analysis. J. Geogr. Sci., 26, pp. 1519-1532.

Friedmann, J., 2006. Four these in the study of China's urbanization. Int. J. Urban Reg. Res., 30, pp. 440-451.

Fu, Z., Liu, B, \& Zhao, D. 2012. Two major problems of urbanization in China: Peri-urbanization population and land use. Sub National Fiscal Research, 4, pp. 18-21. (In Chinese)

Gao, X, Shi, C, Zhai, K., 2018. An evaluation of environmental governance in urban China based on a hesitant fuzzy linguistic analytic network process. Int. J. Environ. Res. Public Health, 15, p. 2456.

Giarlotta, A., Greco, S., 2013. Necessary and possible preference structures. J. Math. Econ., 42 (1), pp. 163-172.

Gilboa, I., Schmeidler, D., 1994. Additive representations of non-additive measures and the Choquet integral. Ann. Oper. Res., 52, pp. 43-65.

Grabisch, M., 1996. The application of fuzzy integrals in multicriteria decision making. Eur. J. Oper. Res., 89, pp. 445-456.

Greco, S., Ishizaka, A., Tasiou, M., Torrisi, G., 2017. On the methodological framework of composite indices: a review of the issues of weighting, aggregation, and robustness. Social Indic. Res., 141 (1), pp. 61-94.

Grupp, H., Mogee, M.E., 2004. Indicators for national science and technology policy: how robust are composite indicators? Res. Policy., 33 (9), pp. 1373-1384.

Guo, Q., Li, R.X., 2003. An evaluation system of development level of agricultural modernization. Journal of Southwest Jiaotong University, 38 (1), pp. 97-101. (in Chinese)

Hommes, C., Sonnemans, J., Tuinstra, J., van de Velden, H., 2008. Expectations and bubbles in asset pricing experiments. Journal of Economic Behavior and Organization, 67 (1), pp. 116-133.

Huang, L., Wu, J., Yan, L., 2015. Defining and measuring urban sustainability: A review of indicators. Landsc. Ecol., 30, pp. 1175-1193.

Ibrahim, M., El-Zaart, A., Adams, C., 2018. Smart Sustainable Cities roadmap: Readiness for transformation towards urban sustainability. Sustain. Cities Soc., 37, pp. 530-540.

Isendahl, C., Smith, M.E., 2013. Sustainable agrarian urbanism: The low-density cities of the Mayas and Aztecs. Cities, 31, pp. 132-143.

Ji, X., Wu, J., Zhu, Q., Sun, J., 2018. Using a hybrid heterogeneous DEA method to benchmark China's sustainable urbanization: An empirical study. Ann. Oper. Res., pp. 1-55.

Ke, S.F., Chen, Z.C., Robson, M., Wen, Y.L., Tiana, X.H., 2015. Evaluating the Implementation Efficiency of the Natural Forest Protection Program in Ten Provinces of Western China by Using Data Envelopment Analysis (DEA). International Forestry Review, 17 (4), pp. 469-476.

Lahdelma, R., Salminen, P., 2001. SMAA-2: Stochastic multicriteria acceptability analysis for group decision making. Oper. Res., 49 (3), pp. 444-454. 
Lees, L., Shin, H., Lopez-Morales, E. 2016. Planetary Gentrification. Polity Press: Cambridge.

Li, J., Deng, J., Gu, Q., Wang, K., Ye, F. 2015. The accelerated urbanization process: A threat to soil resources in eastern China. Sustainability, 7 (6), pp. 7137-7155.

Li, J., Deng, J., Wang, K., Li, J., Huang, T., Lin, Y., Yu, H. 2014. Spatiotemporal patterns of urbanization in a developed region of eastern coastal China. Sustainability, 6 (7), pp. 4042-4058.

Li, N., Xia, Y. J., 2006. Comprehensive evaluation and prediction on the infrastructure modernization level of Ningbo city. Resources and Environment in the Yangtze Basin, 15(2), pp. 136-141. (in Chinese)

Li, T., 2015. Land use dynamics driven by rural industrialization and land finance in the peri-urban areas of China: The examples of Jiangyin and Shunde. Land Use Policy, 45, pp. 117-127.

Li, Y., Jia, L., Wu, W., Yan, J., Liu, Y, 2018. Urbanization for rural sustainability—Rethinking China's urbanization strategy. J. Clean. Prod., 178, pp. 580-586.

Li, Y.H., Chen, C., Wang, Y.F., Liu, Y.S., 2014. Urban-rural transformation and farmland conversion in China: The application of the environmental Kuznets Curve. J. Rural Stud., 36, pp. 311-317.

Ling, J.H., 1998. Deviation between tangible economy and symbolic economy. Economic Perspectives, 6, 45-49. (in Chinese)

Liu, H., Liu, Y., Wang, H., Yang, J., Zhou, X., 2019. Research on the coordinated development of greenization and urbanization based on system dynamics and data envelopment analysis-A case study of Tianjin. J. Clean. Prod., 214, pp. 195-108.

Liu, S., Zhang, P., Jiang, X., Lo, K., 2013. Measuring sustainable urbanization in China: A case study of the coastal Liaoning area. Sustainability Science, 8 (4), pp. 585-594.

Liu, T., Su, C., Jiang, X., 2016. Is China's urbanization convergent? Singap. Econ. Rev., 61, pp. 1-18.

Lu, J. L., 1998. The Theory of Bubble Economy. Economic News (in Chinese).

Luo, T., Xu, M., Huang, T., Ren, X., Bu, X., 2018. Rethinking the intensified disparity in urbanization trajectory of a Chinese coastal province and its implications. Journal of Cleaner Production, 195, pp. 1523-1532.

Ma, Y., Gong, X.S., 2010. Urbanization, agricultural modernization and the adjustment of industrial structure: The calculation and analysis based on VAR. Research and Development, 5, pp. 88-91. (in Chinese)

Marichal, J.L., 2004. Tolerant or intolerant character of interacting criteria in aggregation by the Choquet integral. Eur. J. Oper. Res., 155 (3), pp. 771-791.

Mayer, A.L., 2008. Strengths and weaknesses of common sustainability indices for multidimensional systems. Environ. Int., 34 (2), pp. 277-291.

Mazanec, J. A., Ring, A., (2011). Tourism destination competitiveness: Second thoughts on the world economic forum reports. Tourism Economics, 17(4), pp. 725-751.

McLellan, B., Chapman, A., Aoki, K., 2016. Geography, urbanization and lock-in - considerations for sustainable transitions to decentralized energy systems. J. Clean. Prod., 128, pp. 77-96.

Mendola, D., Volo, S., 2017. Building composite indicators in tourism studies: Measurements and applications in tourism destination competitiveness. Tourism Manag, 59, pp. 541-553.

Miao, J.J., Wang, P., Zhou, J., 2015. Asset bubbles, collateral, and policy analysis. Journal of Monetary Economics, 76 , pp. $57-70$.

Miao, J., Wu, X., 2016. Urbanization, socioeconomic status and health disparity in China. Health and Place, 42, pp. $87-95$.

Mori, K., Yanashita, T., 2015. Methodological framework of sustainability assessment in city sustainability index (CSI): A concept of constraint and maximization indicators. Habitat Int., 45(p1), p. 1014.

Munda, G., 2005. "Measuring Sustainability”: A multi-criterion framework. Environ. Dev. Sustain., 7 (1), pp. 117134. 
Murofushi, S., Soneda, T., 1993. Techniques for Reading Fuzzy Measures (III): Interaction Index. th $^{\text {th }}$ Fuzzy Systems Symposium, Sapporo, Japan, pp. 693-696.

Nardo, M., Saisana, M., Saltelli, A., Tarantola, S., Hoffman, A., Giovannini, E., 2005. Handbook on Constructing Composite Indicators, OECD Statistics.

National Bureau of Statistics, 2017. China Statistical Yearbook. China Statistics Press: Beijing, China. (In Chinese) Newbold, K.B., 1998. Outmigration from California: The role of migrant selectivity. Geogr. Anal., 30, pp. 138-152.

Ng, M.K., Cook, A., Chui, E.W.T., 2001. The road not travelled: A sustainable urban regeneration strategy for Hong Kong. Plan. Pract. Res., 16, pp. 171-183.

Nneji, O., Brooks, C., Ward, C., 2013. Commercial real estate and equity market bubbles: Are they contagious to REITs? Urban Studies, 50 (12), pp. 2496-2516.

Ochoa, J.J., Tan, Y., Qian, Qian, Q.K., Shen, L., Moreno, E.L., 2018. Learning from best practices in sustainable urbanization. Habitat Int., 78, pp. 83-95.

Painter, G., Yu, Z., 2013. Caught in the housing bubble: Immigrants' housing outcomes in traditional gateways and newly emerging destinations. Urban Studies, 51 (4), pp. 781-809.

Palgrave, N., 1987. A dictionary of economics. Lange-Lerner Mechanism, 3, pp. 129-131.

Palit, S., 2014. Application of bubble column reactor in environmental engineering - future directions, future dimensions, visionary and deep comprehension. International Journal of Innovation and Applied Studies, 7(1), pp. 42-48.

Pan, S.Q., Ma, C.Q., 2007. Evaluation indicators system for the city infrastructure development level. Systems Engineering, 25 (7), pp. 88-91.

Qi, Z., Cheng, S., Shen, L., 2000. A Shangri-La strategy for sustain- able development and its practice in the QinghaiTibet plateau. Resour Sci., 22,83-85. (in Chinese).

Ren, T. Z., Li, M., 2006. The reason analysis of rough road of Chinese urbanization. Modern Urban Research, 3, pp. 34-38. (in Chinese).

Rowley, H.V., Peters, G.M., Lundie, S., Moore, S.J., 2012. Aggregating sustainability indicators: Beyond the weighted sum. J. Environ. Manag., 111, pp. 24-33.

Roy, B., 1996. Multicriteria Methodology for Decision Aiding. Dordrecht: Kluwer Academic.

Roy, M., 2009. Planning for sustainable urbanization in fast growing cities: Migration and adaption issues addressed in Dhaka, Bangladesh. Habitat Int., 33, pp. 276-286.

Schwartz, A., 1973. Interpreting the effect of distance on migration. J. Political Econ., 81, pp. 1153-1169.

Shapley, L.S., 1953. A Value for N-person Games. in: Kuhn, H.W., Tucker A.W. (eds.), Contributions to the Theory of Games II. Princeton: Princeton University Press, pp. 307-317.

Shen, L., Ochoa, J., Shah, M.N., Zhang, X., 2011. The application of urban sustainability indicators-A comparison between various practices. Habitat Int., 35, pp. 17-29.

Shen, L., Zhou, J., 2014. Examining the effectiveness of indicators for guiding sustainable urbanization in China. Habitat Int., 44, pp. 111-120.

Shen, L., Zhou, J., Skitmore, M., Xia, B., 2016. Application of a hybrid Entropy-McKinsey Matrix method in evaluating sustainable urbanization: A China case study. Cities, 42, pp. 186-194.

Shome, S., 2013. India's urbanization and business attractiveness by 2020. Cities, 31, pp. 412-416.

Silvia A., Pierluigi, C., Salvatore, C., Alfio, G., Salvatore, G., Marcella, R., 2018. Robust sustainable development assessment with composite indices $\mathrm{T}$ aggregating interacting dimensions: The hierarchical-SMAA-Choquet integral approach. Knowledge-Based Systems, 158, pp. 136-153.

Singh, R.K., Murty, H.R., Gupta, S.K., Dikshit, A.K., 2012. An overview of sustainability assessment methodologies, Ecol. Indic., 15 (1), pp. 281-299. 
Smith, V.L., King, R., Williams, A.W., Boening, M.V. 1993. The robustness of bubbles and crashes in experimental stock markets. Oxford: Oxford Press.

Sun, Y., Liu, N., Zhao, M. 2019. Factors and mechanisms affecting green consumption in China: A multilevel analysis. J. Clean. Prod., 209, pp. 481-493.

Tampouridou, A., Pozoukidou, G., 2018. Smart Cities and Urban Sustainability: Two complementary and interrelated concepts. Reland Int. J. Real Estate Land Plan., 1, pp. 393-401.

Tan, Y., Jiao, L., Shuai, C., Shen, Y., 2018. A system dynamics model for simulating urban sustainability performance: A China case study. J. Clean. Prod., 199, pp. 1107-1115.

Tan, Y., Xu, H., Zhang, X., 2016. Sustainable urbanization in China: A comprehensive literature review. Cities, 55, pp. 82-93.

Teng, H.J., Chang, C.O., Chen, Mi.C., 2017. Housing bubble contagion from city centre to suburbs. Urban Studies, 54 (6), pp. 1463-1481,

Tervonen, T., Figueira, J., 2008. A survey on stochastic multicriteria acceptability analysis methods. J. Multi Criteria Decis. Anal., 15 (1-2), pp. 1-14.

Wang, J., 2011. Measurement of the urbanization bubble in China: Empirical study based on 35 large and middle cities. Urban Development Studies, 18 (11), pp. 8-14. (In Chinese)

Wang, J., Shen, L., Ren, Y., Jorge Ochoa, J., Guo, Z., Yan, H., Wu, Z. 2019. A lessons mining system for searching references to support decision making towards sustainable urbanization. J. Clean. Prod., 209, pp. 451-460.

Wang, S.J., Zhou, C.S., Wang, Z.B., Feng, K.S., Hubacek, K., 2017. The characteristics and drivers of fine particulate matter (PM2.5) distribution in China. J. Clean. Prod., 142, pp. 1800-1809.

Wang, X.Y., Wu, J. N., 2006. Study on new comprehensive evaluation index system of industrialization. The Theory and Practice of Finance and Economics, 27(6), pp. 123-124. (in Chinese)

Wei, D., 2013. Regional development in China: States, globalization and inequality. London: Routledge.

Wu, W., Zhang, M., Qing, Y., Li, Y. 2019. Village resettlement and social relations in transition: the case of Suzhou, China. International Development Planning Review, 41 (3), pp. 269-291.

Xin, L., Jing, H.P., 2010. Setting up evaluation index system and calculation development level of China agricultural modernization. Research of Agricultural Modernization, 21(6), pp. 646-650. (in Chinese)

Xiong, L.J., 1998. Paraphrase and relative theoretical problems of bubble economy. Financial Research, 10, pp. 24 26. (in Chinese).

Xu, Q., 2004. The study on performance and cost of the government leading urbanization. Academia Bimestris, 3, pp. 85-90. (in Chinese).

Yang, J., Luo, Z.H., Zhang, C.Y., 2005. Study on the evaluation system of new-pattern industrialization. Jilin University Journal Social Sciences Edition, 44 (3), pp. 124-129. (in Chinese)

Yang, X., Yue, W., Xu, H., Wu, J., \& He, Y. 2014. Environmental Consequences of Rapid Urbanization in Zhejiang Province, East China. International Journal of Environmental Research and Public Health, 11(7), pp. 70457059.

Ye, C., Chen, M., Duan, J.,Yang, D., 2017. Uneven development, urbanization and production of space in the middlescale region based on the case of Jiangsu province, China. Habitat International, 66, pp. 106-116

Zhai, K.Y., Gao, X., Zhang, Y.R., Wu, M.L., 2019. Perceived sustainable urbanization based on geographically hierarchical data structures in Nanjing, China. Sustainability, 11 (8), pp. 2289-2341.

Zhang, C., Lin, Y., 2012. Panel estimation for urbanization, energy consumption and CO2 emissions: A regional analysis in China. Energy Policy, 49, pp. 488-498.

Zhang, D., Xu, J., Zhang, Y., Wang, J., He, S., \& Zhou, X. (2020). Study on sustainable urbanization literature based on Web of Science, scopus, and China national knowledge infrastructure: A scientometric analysis in CiteSpace. 
J. Clean. Prod., 264, pp. 1-11.

Zhang, L., 2010. The right to the entrepreneurial city in reform-era China. China Rev., 10, pp. 129-156.

Zhang, O., Yuan, H., Tian, X., 2019. Sustainable development in China: Trends, patterns and determinants of the 'five modernizations' in Chinese cities. J. Clean. Prod., 214, pp. 685-695.

Zhang, W.Y., 2006. Lessons from excessive urbanization in Latin America and population control in Beijing. Population Research, 30 (4), pp. 84-89. (in Chinese)

Zhang, Y., Chapple, K., Cao, M., Dennett, A., Smith, D., 2019. Visualising urban gentrification and displacement in Greater London. Environment and Planning A: Economy and Space, 0(0), 1-6.

Zhao, G.R., 2005. To prevent urbanization bubble. Zhongzhou construction, 4, 41. (in Chinese).

Zhao, J., Liang, X., Zhang, X., 1999. System analysis on the definition of sustainable development. Acta Ecologica Sinica., 19, pp. 393-398.

Zhao, P., 2010. Sustainable urban expansion and transportation in a growing megacity: Consequences of urban sprawl for mobility on the urban fringe of Beijing. Habitat Int. 34, 236-243.

Zhi, T.H., Li, Z.F., Jiang, Z.Q., Wei, L.J., Sornette, D., 2019. Is there a housing bubble in China?. Emerging Markets Review, 39, pp. 120-132.

Zhou, D., Xu, J., Wang, L., Lin, Z., 2015. Assessing urbanization quality using structure and function analyses: A case study of the urban agglomeration around Hangzhou Bay (UAHB), China. Habitat Int., 49, pp. 165-176.

Zhou, J.Y., Zhang, X.L., Shen, L.Y., 2015. Urbanization bubble: Four quadrants measurement model. Cities, 46, pp. 8-15. 